\title{
Tensile properties of geosynthetics after installation damage
}

1 Margarida Pinho-Lopes PhD Senior Lecturer, School of Environment and Technology, University of Brighton, Brighton, United Kingdom Formerly Assistant Professor, Department of Civil Engineering, University of Aveiro, Aveiro, Portugal
2. Maria de Lurdes Lopes PhD

Full Professor, Department of Civil Engineering, Faculty of Engineering, University of Porto, Porto, Portugal
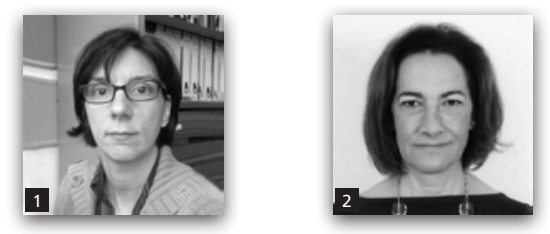

In this paper, data from field installation trials of geosynthetics and laboratory tests are presented and analysed. The influence of several factors was assessed, namely nominal strength and type of geosynthetic, soil, compaction energy and method used to induce installation damage. Visual observations using a scanning electron microscope were performed. From the data collected, reduction factors for installation damage were derived using tensile strength values (traditional approach) and stiffness modulus (for $2 \%$ strain). Relative to the stiffness approach, the results obtained indicate that the traditional approach can be conservative. The reduction factors, determined using the traditional approach, were also compared with interval estimates from the literature. To contribute to supporting a shift from a factor of safety approach to a limit state design, bias statistics to correct the deterministic predictions were determined from the results. Different correlations were also established to enable using these results to interpolate reduction factors for similar installation conditions and/or geosynthetics from the same family of products. Installation damage reduction factors should be used in limit state design (ultimate and serviceability). Nevertheless, the stiffness approach can only be used for limit states where tensile failure of the geosynthetics will not occur.

\section{Notation}

$C_{\mathrm{C}} \quad$ coefficient of curvature (dimensionless)

$C_{\mathrm{U}} \quad$ coefficient of uniformity (dimensionless)

CV coefficient of variation (dimensionless)

$C V_{\text {ult,meas }}$ coefficient of variation of the mean measured strength value for the undamaged specimen (dimensionless)

$D_{50} \quad$ average soil particle size (m)

$D_{\max } \quad$ maximum soil particle size (m)

$J_{20 \text { res }} \quad$ residual secant tensile stiffness modulus at 2\% of strain (dimensionless)

$J_{\text {sec2\% }} \quad$ secant tensile stiffness modulus at 2\% of strain $(\mathrm{N} / \mathrm{m})$

$r f_{\mathrm{B}} \quad$ parameter representing the effect of fill material (dimensionless)

$r f_{\mathrm{C}} \quad$ parameter representing the effect of compaction energy (dimensionless)

$R F_{\mathrm{CR}} \quad$ creep reduction factor (dimensionless)

$R F_{\mathrm{D}} \quad$ durability reduction factor (dimensionless)

$r f_{\mathrm{G}} \quad$ parameter representing the effect of type of geosynthetic (dimensionless)

$R F_{\mathrm{ID}} \quad$ installation damage reduction factor (dimensionless)
$R F_{\text {ID (estim) }}$ estimate (best fit) of the reduction factors for installation damage for the tensile strength (dimensionless)

$R F_{\text {ID (estim) }}^{+}$higher estimate of the reduction factors for installation damage for the tensile strength (dimensionless)

$R F_{\text {ID Jsec2\% }}$ reduction factors for installation damage for the $2 \%$ strain secant stiffness modulus (dimensionless)

$R F_{\text {ID Tmax }}$ reduction factors for installation damage for the tensile strength (dimensionless)

$r f_{\mathrm{N}} \quad$ parameter representing the effect of number of passes (dimensionless)

$T_{\text {al }} \quad$ allowable long-term tensile strength of a geosynthetic reinforcement $(\mathrm{N} / \mathrm{m})$

$T_{\text {al,meas }} \quad$ measured long-term tensile strength of a geosynthetic reinforcement $(\mathrm{N} / \mathrm{m})$

$T_{\text {ID }} \quad$ predicted strength after reduction for installation damage $(\mathrm{N} / \mathrm{m})$

$T_{\mathrm{ID}, \text { meas }} \quad$ measured strength after reduction for installation damage $(\mathrm{N} / \mathrm{m})$

$\bar{T}_{\mathrm{ID}, \text { meas }} \quad$ mean value of the tensile strength of damaged specimens $(\mathrm{N} / \mathrm{m})$ 


\begin{tabular}{|c|c|}
\hline$T_{\max }$ & tensile strength $(\mathrm{N} / \mathrm{m})$ \\
\hline$T_{\text {nom }}$ & nominal peak tensile strength $(\mathrm{N} / \mathrm{m})$ \\
\hline$T_{\text {res }}$ & residual tensile strength (dimensionless) \\
\hline$T_{\text {ult }}$ & ultimate tensile strength $(\mathrm{N} / \mathrm{m})$ \\
\hline $\bar{T}_{\text {ult,meas }}$ & $\begin{array}{l}\text { mean measured strength value for the undamaged } \\
\text { specimen tensile test results }(\mathrm{N} / \mathrm{m})\end{array}$ \\
\hline$U$ & toughness $(\mathrm{N} / \mathrm{m})$ \\
\hline$U_{\text {res }}$ & residual toughness (dimensionless) \\
\hline$W_{\text {opt }}$ & optimum water content (dimensionless) \\
\hline$X_{\mathrm{CR}}$ & bias value for creep (dimensionless) \\
\hline$X_{\mathrm{D}}$ & bias value for durability (dimensionless) \\
\hline$X_{\mathrm{ID}}$ & bias value for installation damage (dimensionless) \\
\hline$X_{\mathrm{R}}$ & bias value for long-term strength (dimensionless) \\
\hline$Y_{\mathrm{dam}}$ & value of property $Y$ for the damaged sample \\
\hline$Y_{\text {res }}$ & residual values after damage of property \\
\hline$Y_{\text {und }}$ & $\begin{array}{l}\text { value of property } Y \text { for the undamaged (intact) } \\
\text { sample }\end{array}$ \\
\hline$\gamma_{\mathrm{dmax}}$ & maximum dry unit weight $\left(\mathrm{N} / \mathrm{m}^{3}\right)$ \\
\hline$\varepsilon$ & peak strain (dimensionless) \\
\hline$\varepsilon_{\text {res }}$ & residual strain (dimensionless) \\
\hline$\Delta R F_{\mathrm{ID}}$ & $\begin{array}{l}\text { variation of the reduction factors for installation } \\
\text { damage when considering the } 2 \% \text { strain secant } \\
\text { stiffness modulus instead of the tensile strength } \\
\text { (dimensionless) }\end{array}$ \\
\hline
\end{tabular}

\section{Introduction}

Geosynthetics have been widely used to replace traditional construction materials and to increase the sustainability of civil engineering works. The application of geosynthetics in environmental geotechnics is very wide (e.g., in landfills and erosion control structures) and the durability of the materials has a key role on their performance.

Installation processes can induce damage, changing their properties before geosynthetics begin to perform the functions they were designed for. In this paper, data from field installation trials and laboratory simulations of installation damage (ID) of geosynthetics are presented and analysed. The paper aims at contributing to the knowledge on the effects of installation damage on the tensile properties of geosynthetics. The paper also intends to assess the conservativeness of using strength reductions, relative to reductions of stiffness, to estimate the response of geosynthetics after installation. With the results, reduction factors for installation damage were derived and compared with interval estimates from the literature. To contribute to supporting a shift from a factor of safety approach to a limit state design, bias statistics to correct the deterministic predictions were determined.

\section{Background}

Among the factors influencing the durability of geosynthetics, installation damage stands out. The resulting stresses are often higher than the stresses to which geosynthetics are subjected during their lifetime and, therefore, superior to the design stresses (Shukla, 2011). In design, installation damage is usually represented by a reduction factor $\left(R F_{\mathrm{ID}}\right)$ expressing the associated tensile strength's losses. Such factor can be obtained from field installation damage tests, where conditions are the same as, or similar to, the project using a common test protocol (Bathurst et al., 2011). According to EN ISO/TR 20432:2007 (IPQ, 2007), if installation damage data for the specific conditions are not available, interpolations can be undertaken, either for the same geosynthetic using measurements with different soils or for other products within the same product line.

Traditionally, the design of geosynthetics uses a factor of safety approach. For reinforcement applications, design codes use Equation 1 (or similar equations) to estimate a geosynthetic reinforcement allowable long-term tensile strength $\left(T_{\text {al }}\right)$ from its ultimate tensile strength $\left(T_{\text {ult }}\right)$ using several reduction factors representing strength loss due to installation damage $\left(R F_{\mathrm{ID}}\right)$, creep $\left(R F_{\mathrm{CR}}\right)$ and degradation due to chemical and biological processes $\left(R F_{\mathrm{D}}\right)$. Such an approach assumes that there is no synergy between these factors. The design ultimate tensile strength can be determined from tensile test results using Equation 2, where $\bar{T}_{\text {ult,meas }}$ is the mean measured strength value for the undamaged specimen tensile test results and $C V_{\text {ult,meas }}$ is the corresponding coefficient of variation.

1. $T_{\mathrm{al}}=\frac{T_{\mathrm{ult}}}{R F_{\mathrm{ID}} \times R F_{\mathrm{CR}} \times R F_{\mathrm{D}}}$

\section{2. $T_{\text {ult }}=\bar{T}_{\text {ult,meas }}\left(1-2 C V_{\text {ult,meas }}\right)$}

Recently, a shift to a limit state design has been aimed at (Bathurst et al., 2011, 2012). These authors propose correcting the deterministic predictions by introducing bias values, determined by the ratio between measured and corresponding predicted value of a variable. Bathurst et al. (2011) suggest Equation 3 to determine the measured long-term tensile strength ( $\left.T_{\mathrm{al}, \text { meas }}\right)$ in a reinforcement, by introducing bias statistics for each of the three strength loss terms from Equation 1.

3.

$$
\begin{aligned}
T_{\mathrm{al}, \text { meas }} & =\frac{T_{\mathrm{ult}}}{R F_{\mathrm{ID}} \times R F_{\mathrm{CR}} \times R F_{\mathrm{D}}} \times X_{\mathrm{R}}=\left(\frac{T_{\mathrm{ult}}}{R F_{\mathrm{ID}}}\right) \\
& \times X_{\mathrm{ID}} \times\left(\frac{1}{R F_{\mathrm{CR}}}\right) \times X_{\mathrm{CR}}\left(\frac{1}{R F_{\mathrm{D}}}\right) \times X_{\mathrm{D}}
\end{aligned}
$$

The bias of the long-term tensile strength of the reinforcement, $X_{\mathrm{R}}$, is expressed as a product of three bias values: $X_{\mathrm{ID}}$, for tensile strength after installation; $X_{\mathrm{CR}}$ and $X_{\mathrm{D}}$, for $R F_{\mathrm{CR}}$ and $R F_{\mathrm{D}}$, respectively. The variability of reinforcement strength immediately after installation can be quantified by the bias value $X_{\mathrm{ID}}$ in Equation 4, where $T_{\mathrm{ID}}$ is the predicted strength after reduction for installation damage (Equation 5), and $R F_{\mathrm{ID}}$ is the installation damage reduction factor (Equation 6) based on project-specific data, determined as the ratio between the mean 
measured strength value for the undamaged specimen tensile test results $\left(\bar{T}_{\text {ult,meas }}\right)$ and the mean value of the tensile strength of the exhumed specimens $\left(\bar{T}_{\mathrm{ID}, \text { meas }}\right)$.

4.

$$
\begin{aligned}
X_{\mathrm{ID}}=\frac{T_{\mathrm{ID}, \text { meas }}}{T_{\mathrm{ID}}} & =\frac{T_{\mathrm{ID}, \text { meas }}}{\left[\frac{\bar{T}_{\mathrm{UD}, \text { meas }}\left(1-2 C V_{\mathrm{ult}, \text { meas }}\right)}{R F_{\mathrm{ID}}}\right]} \\
& =\frac{T_{\mathrm{ID} \text {,meas }}}{\bar{T}_{\mathrm{ID} \text {,meas }}} \times \frac{1}{\left(1-2 C V_{\text {ult,meas }}\right)}
\end{aligned}
$$

5. $\quad T_{\mathrm{ID}}=\frac{T_{\mathrm{ult}}}{R F_{\mathrm{ID}}}$

6. $R F_{\mathrm{ID}}=\frac{\bar{T}_{\mathrm{ult} \text {,meas }}}{\bar{T}_{\mathrm{ID} \text {,meas }}}$

The effects of installation damage on geosynthetics have been studied using laboratory simulations, real-scale simulations or exhumation of installed materials. The degree of mechanical damage resulting from installation depends on geosynthetics' characteristics, grain size, angularity and thickness of the fill material, procedures and construction equipment and climatic conditions (Watn and Chew, 2002).

Watts and Brady (1990) recreated installation damage under real conditions trying to ensure reproducibility and control of the procedures used. Koerner and Koerner (1990) exhumed 75 different geotextiles and geogrids and observed that the number of holes induced is higher when the installation conditions are more severe; a clear trend with strength decrease and with the amount of hole increase was also found. Classifications of the materials depending on the visible damage after installation have been proposed; however, they can be subjective and operator dependent (Greenwood, 1998).

Analysing a large set of test results from field installation trials, Allen and Bathurst (1994) concluded that installation damage typically results in local defects due to fibre cuts, bruising and abrasion, and, for some types of reinforcement, the common interpretation of installation damage is conservative, as the relative losses in geosynthetic modulus (stiffness) in typical wall applications were less than the relative losses in index strength.

Based on a large set of tests, Hufenus et al. (2005) proposed a matrix to estimate the reduction factor for installation damage,

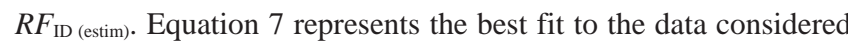
by the authors (coefficient of determination of 0.39) and Equation 8 represents the maximum expected installation damage $\left(R F_{\mathrm{ID} \text { (estim) }}^{+}\right)$. The matrix depends on four parameters $(\geq 1)$ representing the effect of type of geosynthetic (susceptibility to installation damage), $r f_{G}$; fill material, $r f_{\mathrm{B}}$; compaction energy, $r f_{\mathrm{c}}$; and number of passes, $r f_{\mathrm{N}}$.
7. $R F_{\mathrm{ID}(\mathrm{estim})}=r f_{\mathrm{G}} \times r f_{\mathrm{B}} \times r f_{\mathrm{C}} \times r f_{\mathrm{N}}$

8. $R F_{\mathrm{ID}}^{+}$(estim) $=3 R F_{\mathrm{ID}}-1 \cdot 8$

Huang and Wang (2007) compared the tensile properties of two flexible geogrids after installation damage laboratory tests with results of some large-scale field tests. The authors suggested that the standard laboratory test, ENV ISO 10722-1 (IPQ, 1997), could be modified to simulate properly the field installation damage by using an aggregate similar to that used on the site and changing the cyclic load intensity.

Mendes et al. (2007) investigated the tensile response of virgin and damaged nonwoven geotextiles isolated and under confinement conditions, concluding that confinement reduces the effects of installation damage on the tensile behaviour of nonwoven geotextiles and the amount and shape of the soil particles intruding the geotextile pores influence the tensile stiffness.

\section{Geosynthetics}

Six geosynthetics were tested in machine direction: two woven geotextiles, GTX1 and GTX2; two woven geogrids, GGw1 and GGw2; one extruded geogrid, GGe; and one reinforcement geocomposite, GC. Some of their properties and more detailed descriptions are included in Table 1.

\section{Laboratory tests}

Test programme

Within the scope of this study, field and laboratory tests were included to investigate installation damage on the six geosynthetics analysed. Wide-width tensile tests (EN ISO 10319; IPQ, 2008)

\begin{tabular}{lccc}
\hline Geosynthetic & \multicolumn{1}{c}{ Description } & $\begin{array}{c}\text { Mass per } \\
\text { unit area: } \\
\mathrm{g} / \mathrm{m}^{2}\end{array}$ & $\begin{array}{c}T_{\text {nom: }} \\
\mathrm{kN} / \mathrm{m}\end{array}$ \\
& & 110 & 22 \\
\hline GTX1 & PP woven biaxial geotextile & 10 & 44 \\
GTX2 & PP woven biaxial geotextile & 220 & 60 \\
GGW1 & PET uniaxial woven geogrid & - & 65 \\
GGw2 & PET biaxial woven geogrid & - & 55 \\
GGe & HDPE extruded uniaxial & - & 64.5 \\
& geogrid & & \\
GC & Grid aramid layered with a & - & 40 \\
& PET nonwoven geotextile & & \\
\hline
\end{tabular}

PP, polypropylene; PET, polyester; HDPE, high-density polyethylene. 
Type of installation damage test

\begin{tabular}{|c|c|c|c|c|c|c|}
\hline \multirow{3}{*}{ Synthetic aggregate } & \multicolumn{6}{|c|}{ Field } \\
\hline & \multicolumn{2}{|c|}{ Soil 1} & \multicolumn{2}{|c|}{ Soil 2} & \multicolumn{2}{|c|}{ Soil 3} \\
\hline & CE1 & CE2 & CE1 & CE2 & CE1 & CE2 \\
\hline$L A B$ & S1-CE1 & S2-CE2 & S2-CE1 & S2-CE2 & S3-CE1 & S3-CE2 \\
\hline$x$ & $x$ & $x$ & & $x$ & & \\
\hline$x$ & $x$ & $x$ & & $x$ & & \\
\hline$x$ & & & $x$ & $x$ & & \\
\hline$x$ & & & & & $x$ & $x$ \\
\hline & & & & & $x$ & $x$ \\
\hline$x$ & & & $x$ & $x$ & & \\
\hline
\end{tabular}

S1, soil 1 ; S2, soil 2 ; S3, soil 3; CE1, compaction energy 1; CE2, compaction energy 2 .

$\mathrm{x}$ - test was carried out.

Table 2. Installation damage test programme

were used to mechanically characterise the geosynthetics. Visual damages were assessed from scanning electron microscope (SEM) observations. Table 2 summarises the test programme implemented. The different types of damaged samples are referred to using a code. The following are some examples: samples after installation damage in the laboratory, ID-LAB, and samples obtained after field installation damage in soil 1 (S1) with compaction energy 2 (CE2), ID-S1-CE2.

\section{Field trials}

To simulate installation damage, trial embankments with the geosynthetics were prepared in the field, in three different roadway construction sites. Common procedures for soil reinforcement applications were used. Temporary embankments were built, installing the geosynthetics between layers of compacted soil and later recovered to be tested. Each set of embankments was built using a different soil (Figure 1 and Table 3): soil 1 (S1), soil 2 (S2) and soil 3 (S3). The same equipment was used in all construction sites to spread, level and compact the soils. Two different energies (90\% (CE1) and 98\% (CE2) of the standard Proctor of the soil) were considered, which resulted in building two embankments on each construction site (total of six). A nuclear density meter was used to control the compaction. The standard Proctor of the soil was defined using the procedures described in ASTM D698 (ASTM, 1991).

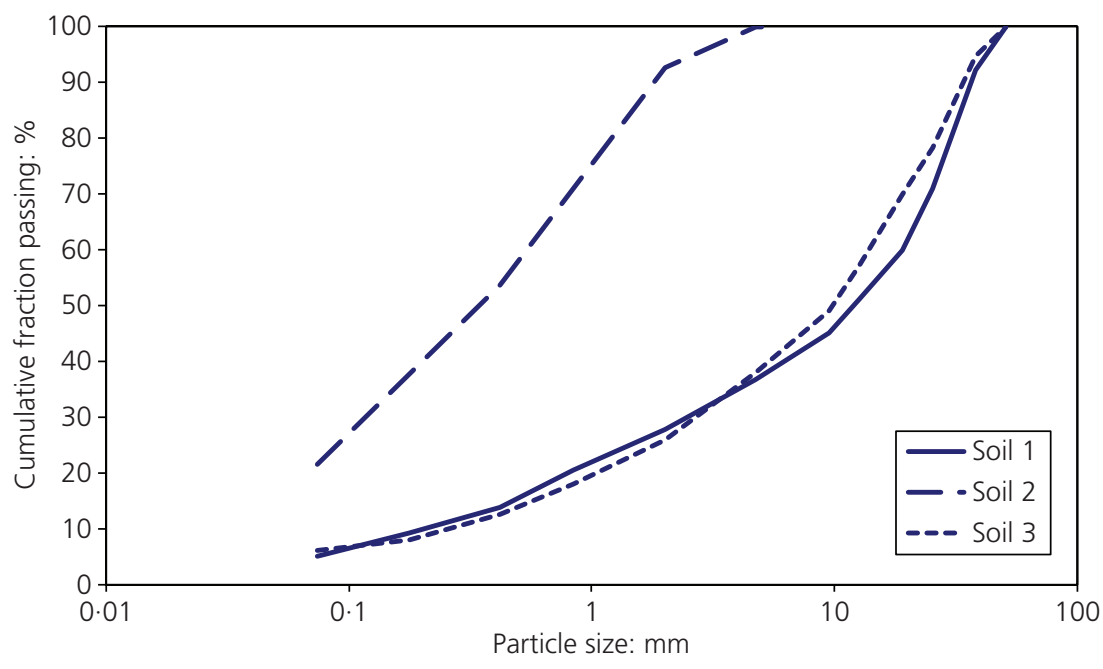

Figure 1. Particle-size distributions of soils 1 to 3 


\begin{tabular}{|c|c|c|c|c|c|c|c|c|}
\hline \multirow[t]{2}{*}{ Soils } & \multirow[t]{2}{*}{$\%<0.074 \mathrm{~mm}$} & \multirow[t]{2}{*}{$D_{50}: \mathrm{mm}$} & \multirow[t]{2}{*}{$D_{\max }: \mathrm{mm}$} & \multirow[t]{2}{*}{$C_{u}$} & \multirow[t]{2}{*}{$C_{c}$} & \multicolumn{2}{|c|}{ Proctor } & \multirow[t]{2}{*}{ Unified soil classification } \\
\hline & & & & & & $\gamma_{\mathrm{dmax}}: \mathrm{kN} / \mathrm{m}^{3}$ & $W_{\text {opt: }} \%$ & \\
\hline S1 & $5 \cdot 18$ & $11 \cdot 78$ & $50 \cdot 80$ & $87 \cdot 81$ & $1 \cdot 71$ & $20 \cdot 70$ & $7 \cdot 80$ & GW - well-graded gravel with sand \\
\hline S2 & $21 \cdot 53$ & 0.38 & $5 \cdot 00$ & $9 \cdot 64$ & 0.58 & $18 \cdot 84$ & $11 \cdot 30$ & SM - silty sand \\
\hline S3 & $6 \cdot 10$ & $9 \cdot 88$ & $50 \cdot 00$ & $50 \cdot 43$ & $2 \cdot 17$ & $21 \cdot 29$ & $6 \cdot 20$ & GW-GM - well-graded gravel with silt \\
\hline
\end{tabular}

Table 3. Soils

Soil was poured, spread and compacted over the road platform. The resulting soil layer (200 mm high) was the foundation of the embankments and, where the geosynthetics were placed, free from wrinkles. Two additional soil layers (each $200 \mathrm{~mm}$ high) were built over the geosynthetics. When the embankments were completed, the soil was carefully removed to avoid additional damage. Some characteristics of the compaction equipment are summarised in Table 4.

\section{Laboratory simulations}

The laboratory simulations of installation damage followed the procedures in ENV ISO 10722-1:1998 (IPQ, 1998). The test consists in placing a specimen of geosynthetic between two layers (each $150 \mathrm{~mm}$ high) of a synthetic aggregate (sintered aluminium oxide, with sizes ranging between 5 and $10 \mathrm{~mm}$ ) and submitting the assembly to a cyclic loading (5 to $900 \mathrm{kPa}$, frequency of

\begin{tabular}{lcc}
\hline Weight & Value & Unit \\
\hline $\begin{array}{l}\text { Operating weight CECE } \\
\text { Operating weight (open cabin) } \\
\quad \text { Linear }\end{array}$ & 15600 & $\mathrm{~kg}$ \\
Loads & 43.9 & $\mathrm{~kg}$ \\
$\quad$ Front & & $\mathrm{kg} / \mathrm{m}$ \\
$\quad$ Back & 9000 & $\mathrm{~kg}$ \\
\hline $\begin{array}{l}\text { Cylinder dimensions } \\
\text { Width }\end{array}$ & 6600 & $\mathrm{~kg}$ \\
\hline $\begin{array}{l}\text { Diameter } \\
\text { Thickness }\end{array}$ & 2100 & $\mathrm{~mm}$ \\
Tyres & 1500 & - \\
\hline
\end{tabular}

\section{Vibration}

\begin{tabular}{lcc}
\hline Amplitudes & $2 \cdot 0 / 0 \cdot 8$ & $\mathrm{~mm}$ \\
Frequencies & $28 / 38$ & $\mathrm{~Hz}$ \\
Centrifuge force & $280 / 220$ & $\mathrm{kN}$
\end{tabular}

Table 4. Compaction equipment characteristics
$1 \mathrm{~Hz}, 200$ cycles). At the end of the test, the aggregate is carefully removed, avoiding additional damage.

\section{Characterisation of the geosynthetics}

SEM observations allowed the visual characterisation of the geosynthetics (intact and damaged). The equipment used was a high-resolution SEM model JEOL JSM 6301F. Visual observation of geosynthetics was in some cases prevented by the accumulation of dust and dirt after installation. The materials were cleaned, avoiding additional abrasion or damage. To take specimens, an objective geometric criterion was used: similar positions in the geosynthetics' samples. Before cutting the specimens, a global visual assessment of the damage induced was undertaken to guarantee that the specimens (always to be cut within the designated area) were representative of the corresponding sample. The small scale of the SEM specimens relative to civil engineering works is evident, as the holders are $\sim 2 \mathrm{~cm}^{2}$ (plan). Images were taken using different augmentation factors (10 to 2000 times).

The short-term mechanical behaviour of the geosynthetics was characterised by wide-width tensile tests (EN ISO 10319:2008; IPQ, 2008).

\section{Discussion}

Visual inspections

Figures 2 to 5 include SEM pictures of samples of geotextiles GTX1 and GTX2, woven geogrid GGw1 and geocomposite GC, respectively. Additional images are included as supplementary material to this paper (available online).

The woven structure and the PP tapes of geotextile GTX1 are clear in the images. Visually, GTX1 seems more affected by installation damage induced in the laboratory than on the field. After installation damage induced in the laboratory, there were several polypropylene (PP) tapes cut and some lamination of the surface of those tapes. Field installation damage altered the surface of GTX1 (which looked rougher). After field installation damage in soil 1 with the lowest compaction energy (ID-S1-CE1), the visible damage was localised, including evidence of puncturing (Figure 2). Most of the surface of geotextile GTX1 seemed affected by installation damage in soil 2 compacted to $98 \%$ of the standard 


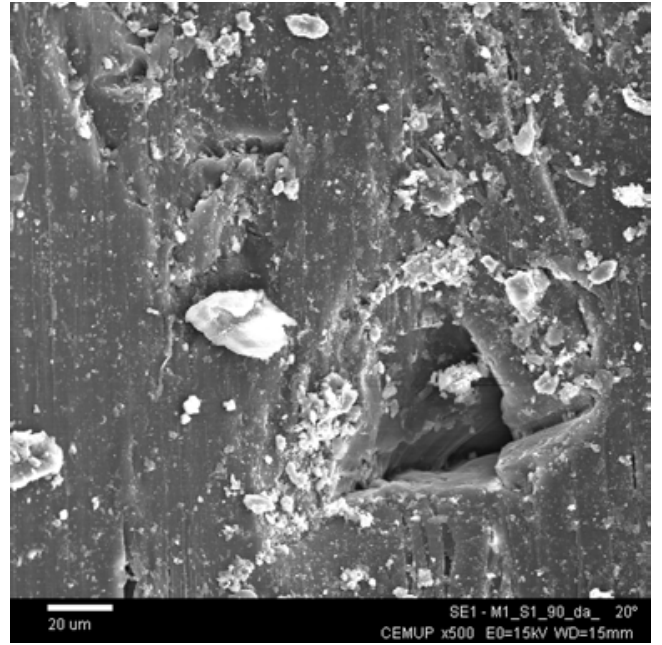

Figure 2. SEM image of geotextile GTX1 installed in soil 1 compacted to compaction energy 1, ID-S1-CE1, ×500

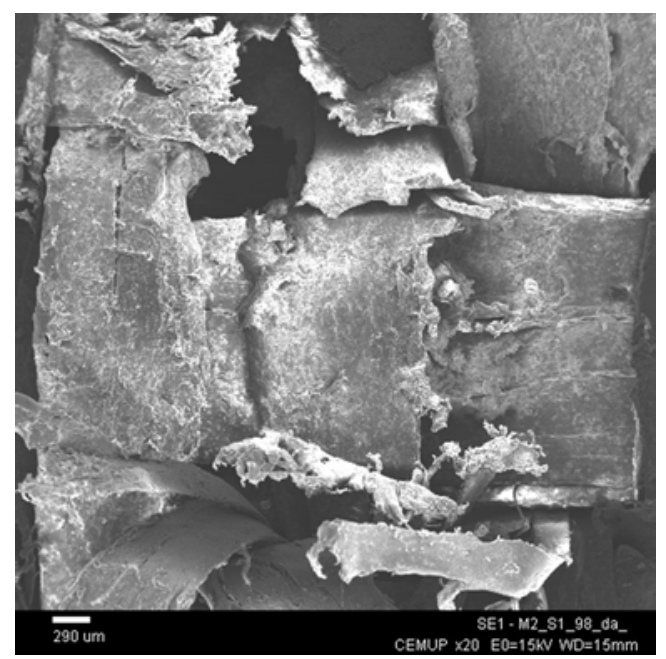

Figure 3. SEM images of geotextile GTX2 installed in soil 1 compacted to compaction energy 2, ID-S1-CE2, ×20

Proctor, ID-S1-CE2. Although installing geotextile GTX1 in soil 2 with the highest compaction energy (ID-S2-CE2) also resulted in a visually changed overall aspect, the surface of the samples seemed to be less damaged and more similar to that of the intact material.

Geotextile GTX2 evidenced cuts and surface lamination after installation damage induced in the laboratory. After field installation damage, particularly with soil 1 and compaction energy 2 (98\% of the standard Proctor), ID-S1-CE2, there were holes and cuts in the tapes (Figure 3), as well as puncturing and a rougher surface. Installation in soil 1 with the lowest compaction energy,

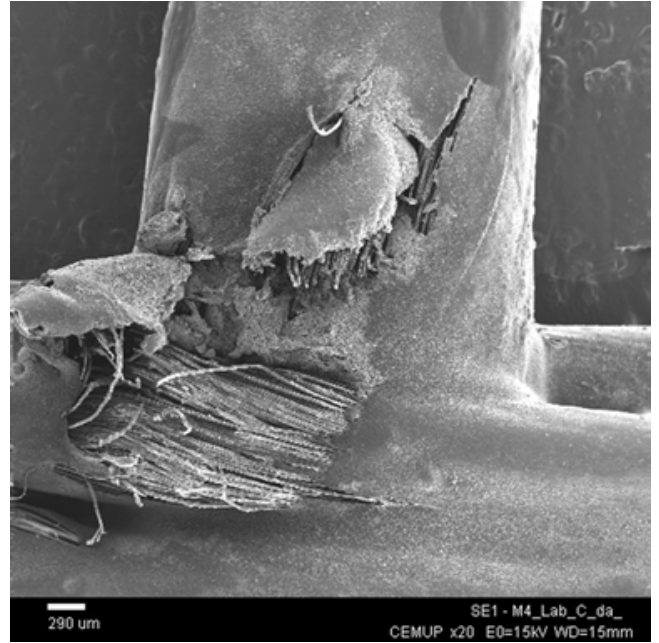

Figure 4. SEM images of woven geogrid GGw1 damaged in the laboratory, ID LAB, $\times 20$

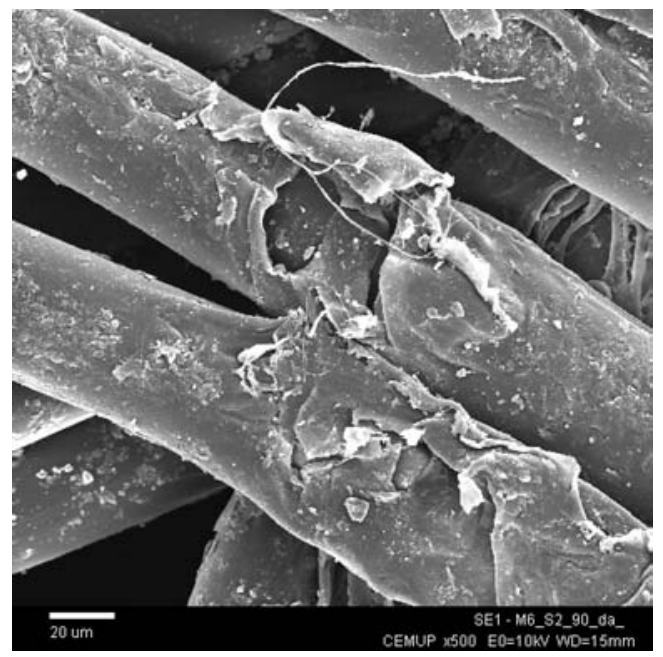

Figure 5. SEM images of geocomposite GC installed in soil 2 compacted to compaction energy 1, ID-S2-CE1, ×500

ID-S1-CE1, and, particularly, in soil 2 with the highest compaction energy, ID-S2-CE2, seemed to be the least aggressive, as changes observed were less evident and more localised.

The woven geogrid GGw1 was most affected by installation damage induced in the laboratory, as part of its coating was removed and some underlying fibres were cut (Figure 4). After installation in soil 2, ID-S2, a similar mechanism could be observed, though on a much smaller scale, as well as some puncturing.

For observation purposes, the two elements constituting geocomposite GC were separated (grid and geotextile). As the 
geotextile covered both sides of the grid, the latter was protected from the induced installation damage. Nevertheless, the grid was also affected. There were geotextile fibres cut after the laboratory simulations of installation damage, which were less evident for the other damaged samples. In all damaged samples of geocomposite GC, the coating was partially removed (Figure 5).

Fibre cutting typically occurs when a sharp-edged material (e.g., stone) acts as a knife cutting the fibres of the geosynthetics (e.g., woven geotextiles, geogrids and strips) (Watn and Chew, 2002). These authors also mentioned that coating will reduce the susceptibility for fibre cutting and diminish the tensile strength's reductions. The SEM images obtained in the present study enabled confirming that, in some cases, the coating was not sufficient to protect fibres from being cut. The observations made indicated that the aggregate used in the laboratory test to induce installation damage apparently resulted in more cuts. Soil 2 had particles smaller and rounder than soil 1 , resulting in less severe damage. Further information on the influence of the type of soil is included in Section 5·6.

\section{Summary of test results}

Table 5 summarises the tensile test results in terms of mean values (five specimens) and corresponding coefficient of variation (CV) of tensile strength $\left(T_{\max }\right)$, peak strain $(\varepsilon)$, $2 \%$ strain secant stiffness modulus $\left(J_{\mathrm{sec} 2 \%}\right)$ and toughness $(U)$. The toughness, work done until rupture, is defined as the area under the loadstrain curve until failure. To determine it, each specimen's loadstrain curve was approximated by polymeric curves (sixth-order polynomials), fitting the tensile test data up to the peak values. The corresponding coefficients of determination were always near 1 . For the samples for which only the peak strain was available, the toughness was determined approximately (as suggested in EN ISO 10139) as a triangle with base equal to the peak strain and height equal to the tensile strength.

Table 6 includes design ultimate tensile strength $\left(T_{\text {ult }}\right)$ for intact and damaged materials determined from Equation 2, reduction factors for installation using results for the tensile strength $\left(R F_{\mathrm{ID} \text { Tmax }}\right)$ and for the $2 \%$ strain secant stiffness modulus $\left(R F_{\mathrm{ID} \mathrm{Jsec} 2 \%}\right)$ determined from Equation 9, variation of the installation damage reduction

\begin{tabular}{|c|c|c|c|c|c|c|c|c|c|}
\hline Material & Sample & $T_{\max }: \mathrm{kN} / \mathrm{m}$ & CV: \% & $\varepsilon: \%$ & CV: \% & $J_{\mathrm{sec} 2 \%}: \mathrm{kN} / \mathrm{m}$ & CV: \% & $U: k N / m$ & CV: \% \\
\hline \multirow[t]{5}{*}{ GTX1 } & INT & $25 \cdot 53$ & 1.69 & $23 \cdot 86$ & $5 \cdot 42$ & $104 \cdot 37$ & $5 \cdot 95$ & $341 \cdot 35$ & $4 \cdot 50$ \\
\hline & ID-LAB & $2 \cdot 57$ & $21 \cdot 29$ & $2 \cdot 17$ & $25 \cdot 14$ & - & - & 2.90 & $41 \cdot 32$ \\
\hline & ID-S1-CE1 & $6 \cdot 33$ & $9 \cdot 78$ & $9 \cdot 24$ & $30 \cdot 86$ & $81 \cdot 82$ & 8.04 & 37.93 & 46.73 \\
\hline & ID-S1-CE2 & $4 \cdot 72$ & $23 \cdot 18$ & $6 \cdot 45$ & 31.06 & $85 \cdot 10$ & $2 \cdot 84$ & $17 \cdot 94$ & 54.97 \\
\hline & ID-S2-CE2 & $16 \cdot 53$ & 14.51 & $15 \cdot 22$ & $10 \cdot 86$ & 88.63 & $16 \cdot 19$ & 125.95 & $25 \cdot 15$ \\
\hline \multirow[t]{5}{*}{ GTX2 } & INT & $41 \cdot 72$ & $3 \cdot 38$ & $16 \cdot 99$ & $7 \cdot 64$ & 258.76 & $12 \cdot 23$ & 383.91 & 11.47 \\
\hline & ID-LAB & $11 \cdot 58$ & $5 \cdot 14$ & $4 \cdot 38$ & $6 \cdot 68$ & $253 \cdot 53$ & $18 \cdot 58$ & $29 \cdot 65$ & 14.27 \\
\hline & ID-S1-CE1 & $16 \cdot 40$ & 10.06 & 8.89 & 3.97 & 177.04 & $6 \cdot 14$ & 82.48 & 11.09 \\
\hline & ID-S1-CE2 & $10 \cdot 32$ & 18.08 & $7 \cdot 56$ & $31 \cdot 45$ & $155 \cdot 26$ & $9 \cdot 94$ & 48.04 & 54.61 \\
\hline & ID-S2-CE2 & $31 \cdot 84$ & $3 \cdot 90$ & $13 \cdot 83$ & $5 \cdot 29$ & 221.95 & $13 \cdot 83$ & 225.69 & $7 \cdot 04$ \\
\hline \multirow[t]{4}{*}{ GGw1 } & INT & $66 \cdot 85$ & $1 \cdot 16$ & 14.02 & $4 \cdot 40$ & 585.00 & $2 \cdot 33$ & $387 \cdot 78$ & 4.92 \\
\hline & ID-LAB & $50 \cdot 50$ & $9 \cdot 47$ & $11 \cdot 39$ & $49 \cdot 70$ & $547 \cdot 61$ & $5 \cdot 36$ & $327 \cdot 01$ & 14.54 \\
\hline & ID-S2-CE1 & 63.00 & $4 \cdot 32$ & $14 \cdot 72$ & $3 \cdot 35$ & $576 \cdot 78$ & 0.51 & $387 \cdot 54$ & 9.02 \\
\hline & ID-S2-CE2 & $59 \cdot 23$ & 7.69 & $14 \cdot 20$ & 3.97 & $580 \cdot 14$ & 1.41 & $360 \cdot 50$ & 8.08 \\
\hline \multirow[t]{4}{*}{ GGw2 } & INT & $70 \cdot 78$ & $4 \cdot 31$ & $16 \cdot 01$ & $6 \cdot 17$ & $590 \cdot 43$ & $1 \cdot 80$ & $425 \cdot 11$ & $9 \cdot 51$ \\
\hline & ID-LAB ${ }^{b}$ & $51 \cdot 11$ & $12 \cdot 19$ & - & - & - & - & - & - \\
\hline & ID-S3-CE1 & $57 \cdot 51$ & 7.91 & $15 \cdot 15$ & 11.01 & $593 \cdot 51$ & 1.45 & $388 \cdot 57$ & $16 \cdot 33$ \\
\hline & ID-S3-CE2 & $61 \cdot 52$ & $7 \cdot 46$ & 14.90 & $5 \cdot 91$ & $586 \cdot 05$ & $1 \cdot 25$ & 395.07 & $10 \cdot 16$ \\
\hline \multirow[t]{3}{*}{ GGe } & INT & $61 \cdot 61$ & 4.95 & $17 \cdot 14$ & $4 \cdot 82$ & $943 \cdot 30$ & $7 \cdot 06$ & $832 \cdot 45$ & 4.87 \\
\hline & ID-S3-CE1 & 57.75 & $3 \cdot 14$ & 14.63 & $13 \cdot 23$ & $940 \cdot 74$ & $7 \cdot 16$ & $588 \cdot 50$ & $24 \cdot 17$ \\
\hline & ID-S3-CE2 & $50 \cdot 62$ & $11 \cdot 14$ & $11 \cdot 41$ & $9 \cdot 61$ & $928 \cdot 37$ & $1 \cdot 44$ & 342.97 & $19 \cdot 44$ \\
\hline \multirow[t]{4}{*}{ GC } & $\mathrm{INT}^{\mathrm{a}}$ & $42 \cdot 68$ & 0.77 & $4 \cdot 38$ & $5 \cdot 91$ & - & - & $93 \cdot 48$ & $6 \cdot 17$ \\
\hline & $\mathrm{LAB}$ & 15.93 & $3 \cdot 70$ & $2 \cdot 88$ & $25 \cdot 65$ & $677 \cdot 78$ & $3 \cdot 36$ & $28 \cdot 21$ & $43 \cdot 64$ \\
\hline & ID-S2-CE1 & 33.66 & $7 \cdot 51$ & $2 \cdot 94$ & 6.02 & $1200 \cdot 33$ & $4 \cdot 27$ & $45 \cdot 13$ & 34.02 \\
\hline & ID-S2-CE2 & $33 \cdot 56$ & $7 \cdot 41$ & $3 \cdot 24$ & $15 \cdot 42$ & $1139 \cdot 96$ & $8 \cdot 26$ & 55.97 & 19.67 \\
\hline
\end{tabular}

a Due to problems with the data acquisition, only the peak values are available.

b Strains measured as the distance between the jaws in the equipment (not comparable with the other values).

Table 5. Results of the tensile tests before and after installation damage (mean values and corresponding coefficients of variation) 


\begin{tabular}{|c|c|c|c|c|c|c|c|}
\hline \multirow[t]{2}{*}{ Material } & \multirow[t]{2}{*}{ Sample } & \multirow[t]{2}{*}{$\begin{array}{c}T_{\text {ult: }}: \mathrm{kN} / \mathrm{m} \\
\text { (Equation 2) }\end{array}$} & \multirow[t]{2}{*}{$\begin{array}{c}R F_{\mathrm{DDI} \text { Tmax }} \\
\text { (Equation 9) }\end{array}$} & \multirow[t]{2}{*}{$\begin{array}{c}R F_{\mathrm{DDI}} \mathrm{sec} 2 \% \\
\text { (Equation 9) }\end{array}$} & \multirow[t]{2}{*}{$\begin{array}{c}\Delta R F_{\mathrm{DDI}}: \% \\
\text { (Equation } 10)\end{array}$} & \multicolumn{2}{|c|}{$\begin{array}{c}X_{\mathrm{ID}} \\
\text { (Equation 4) }\end{array}$} \\
\hline & & & & & & Mean & CV: \% \\
\hline \multirow[t]{5}{*}{ GTX1 } & INT & $24 \cdot 67$ & - & - & - & - & - \\
\hline & ID-LAB & 1.48 & 9.93 & - & - & 1.07 & $21 \cdot 29$ \\
\hline & ID-S1-CE1 & $5 \cdot 09$ & 4.03 & $1 \cdot 28$ & $-68 \cdot 37$ & 1.07 & $9 \cdot 78$ \\
\hline & ID-S1-CE2 & $2 \cdot 53$ & 5.41 & 1.23 & $-77 \cdot 33$ & 1.07 & $23 \cdot 18$ \\
\hline & ID-S2-CE2 & 11.73 & $1 \cdot 54$ & $1 \cdot 18$ & $-23 \cdot 75$ & 1.07 & $14 \cdot 51$ \\
\hline \multirow[t]{5}{*}{ GTX2 } & INT & 38.90 & - & - & - & - & - \\
\hline & ID-LAB & $10 \cdot 39$ & $3 \cdot 60$ & 1.02 & -71.67 & $1 \cdot 15$ & $5 \cdot 14$ \\
\hline & ID-S1-CE1 & $13 \cdot 10$ & $2 \cdot 54$ & 1.46 & $-42 \cdot 55$ & $1 \cdot 15$ & $10 \cdot 06$ \\
\hline & ID-S1-CE2 & $6 \cdot 59$ & 4.04 & 1.67 & -58.77 & $1 \cdot 15$ & 18.08 \\
\hline & ID-S2-CE2 & $29 \cdot 36$ & $1 \cdot 31$ & $1 \cdot 17$ & -11.02 & $1 \cdot 15$ & 3.90 \\
\hline \multirow[t]{4}{*}{ GGw1 } & INT & $65 \cdot 30$ & - & - & - & - & - \\
\hline & ID-LAB & $40 \cdot 94$ & $1 \cdot 32$ & 1.07 & $-19 \cdot 30$ & 1.05 & $9 \cdot 47$ \\
\hline & ID-S2-CE1 & $57 \cdot 56$ & 1.06 & 1.01 & -4.42 & 1.05 & $4 \cdot 32$ \\
\hline & ID-S2-CE2 & $50 \cdot 12$ & $1 \cdot 13$ & $1 \cdot 01$ & $-10 \cdot 66$ & 1.05 & $7 \cdot 69$ \\
\hline \multirow[t]{4}{*}{ GGw2 } & INT & $64 \cdot 68$ & - & - & - & - & - \\
\hline & ID-LAB & 38.65 & $1 \cdot 38$ & - & - & - & - \\
\hline & ID-S3-CE1 & $48 \cdot 41$ & $1 \cdot 23$ & $0.99^{a}$ & $-19 \cdot 17$ & $1 \cdot 20$ & 7.91 \\
\hline & ID-S3-CE2 & $52 \cdot 34$ & $1 \cdot 15$ & $1 \cdot 01$ & $-12 \cdot 43$ & $1 \cdot 20$ & $7 \cdot 46$ \\
\hline \multirow[t]{3}{*}{ GGe } & INT & $55 \cdot 51$ & - & - & - & - & - \\
\hline & ID-S3-CE1 & $54 \cdot 12$ & 1.07 & 1.00 & -6.01 & 1.23 & $3 \cdot 14$ \\
\hline & ID-S3-CE2 & $39 \cdot 34$ & $1 \cdot 22$ & 1.02 & $-16 \cdot 52$ & 1.23 & $11 \cdot 14$ \\
\hline \multirow[t]{4}{*}{$\mathrm{GC}$} & INT & $42 \cdot 02$ & - & - & - & - & - \\
\hline & $L A B$ & 14.75 & $2 \cdot 68$ & - & - & 1.03 & 3.70 \\
\hline & ID-S2-CE1 & 28.60 & $1 \cdot 27$ & - & - & 1.03 & $7 \cdot 51$ \\
\hline & ID-S2-CE2 & 28.59 & $1 \cdot 27$ & - & - & 1.03 & $7 \cdot 41$ \\
\hline
\end{tabular}

a Minimum value for design, 1.00.

$C V$, coefficient of variation.

Table 6. Tensile test results (ultimate values)

factors $\left(\Delta R F_{\mathrm{ID}}\right.$, Equation 10) and bias statistics for installation damage $\left(X_{\mathrm{ID}}\right)$ using Equation 4, represented by the corresponding mean and $\mathrm{CV}$. The reduction factors for installation damage were determined from Equation 9, where $Y_{\mathrm{dam}}$ is the value of property $Y$ after installation damage and $Y_{\text {und }}$ is the corresponding value for the undamaged material.

9. $\quad R F_{\mathrm{ID}}=\frac{Y_{\text {und }}}{Y_{\text {dam }}}$

10. $\Delta R F_{\mathrm{ID}}=\frac{R F_{\mathrm{ID} J s e c} 2 \%-R F_{\mathrm{ID} T \max }}{R F_{\mathrm{ID} \operatorname{Tmax}}} \times 100(\%)$

According to Allen and Bathurst (1994), for some materials (woven and uniaxial geogrid products), the residual stiffness modulus is a 'more rational quantitative measure of resistance to site installation damage'. To verify this hypothesis, reduction factors for installation damage using the $2 \%$ strain stiffness value as a reference property were derived $\left(R F_{\mathrm{ID} J \mathrm{Jse} 2 \%}\right)$. The variation in the reduction factor ( $\Delta R F_{\mathrm{ID}}$ ) when considering $J_{\text {sec } 2 \%}$, instead of $T_{\max }$, was calculated (Equation 10). Assessing the conservativeness of considering the tensile strength response after installation damage instead of the corresponding changes in stiffness was aimed at. The reduction factor for installation damage using the $2 \%$ strain stiffness $\left(R F_{\text {ID Jsec2 } \%)}\right.$ could be used to design geosynthetics for serviceability limit states and for some ultimate limit state (not involving the tensile failure of the geosynthetic). Residual values after damage ( $Y_{\text {res, }}$ in per cent) of the relevant properties were determined as the ratio of $Y_{\text {dam }}$ and $Y_{\text {und }}$. Therefore, the residual value of the tensile strength after damage is the inverse of the corresponding reduction factor.

\section{Influence of the nominal tensile strength}

To analyse the influence of the nominal strength of the geosynthetics, the response of materials with the same structure but with different 
nominal tensile strength values was analysed: geotextiles GTX1 and GTX2, with 22 and $44 \mathrm{kN} / \mathrm{m}$, respectively. Figure 6 includes the corresponding residual values of tensile strength $\left(T_{\text {res }}\right)$, peak strain $\left(\varepsilon_{\text {res }}\right), 2 \%$ strain stiffness modulus ( $\left.J_{2 \% \text { res }}\right)$ and toughness $\left(U_{\text {res }}\right)$. Except for the $2 \%$ strain stiffness modulus, the increase of $100 \%$ on the nominal strength resulted in an increase of the different assessed properties. The tensile strength increased between $18 \%$ (after installation damage in soil 2 with the highest compaction energy, ID-S2-CE2) and 176\% (after laboratory installation damage). The peak strain increased between 28\% (after installation damage in soil 2 with the highest compaction energy, ID-S2-CE2) and $183 \%$ (after laboratory installation damage); for the toughness, such increase ranged between 59\% (after installation damage in soil 2 with the highest compaction energy, ID-S2-CE2) and 114\% (after laboratory installation damage). After installation in soil 1, the residual value of the $2 \%$ strain stiffness modulus decreased $13 \%$ and 26\% for compaction energies 1 and 2, respectively, when using GTX2 instead of GTX1; after installation in soil 2 with the highest compaction energy (ID-S2-CE2), the residual value of the $2 \%$ strain stiffness modulus increased $1 \%$.

For these materials and test conditions, increasing the nominal strength of the geosynthetic resulted in an increase of tensile strength after installation damage, confirming the assumption that stronger geosynthetics better survive the installation processes. However, such a concept does not reflect the changes observed for the $2 \%$ strain stiffness modulus, which, in many cases, is a better indicator of the geosynthetics' performance.
With similar structures, geotextiles GTX1 and GTX2 are constituted by tapes of different widths and in different quantities. When a tape is damaged, adjacent elements have to support additional tensile forces. The force is progressively increased, leading to the failure of bearing members. As a result, after installation damage, for higher tensile forces applied during the tensile tests, failure occurred earlier than for the corresponding intact material. GTX2, with the highest number of tapes as well as the widest ones, was more able to redistribute loads than GTX1. While the applied tensile forces were low and did not cause a significant number of failures in the geotextile's bearing members, the material's response was more similar to that of the intact geotextile, thus resulting in the smallest variations of the stiffness values.

\section{Influence of the type of geosynthetic}

Figure 7 refers to geotextile GTX1 and geocomposite GC, with different types of and identical nominal tensile strength $(40 \mathrm{kN} / \mathrm{m})$. For similar installation damage conditions, both in the laboratory (ID-LAB) and in soil 2 with the highest compaction energy (ID-S2-CE2), the response of geocomposite GC is always the best. Using geocomposite GC instead of geotextile GTX1 led to an increase of residual tensile strength between 270\% (after damage induced in the laboratory) and 21\% (when installed in soil 2 using compaction energy 2, ID-S2-CE2), residual peak strain $\left(\varepsilon_{\text {res }}\right)$ between $623 \%$ (induced in the laboratory) and 16\% (after installation in the field with soil 2 and the highest compaction energy, ID-S2-CE2) and residual toughness ( $\left.U_{\text {res }}\right)$ between 3452\%

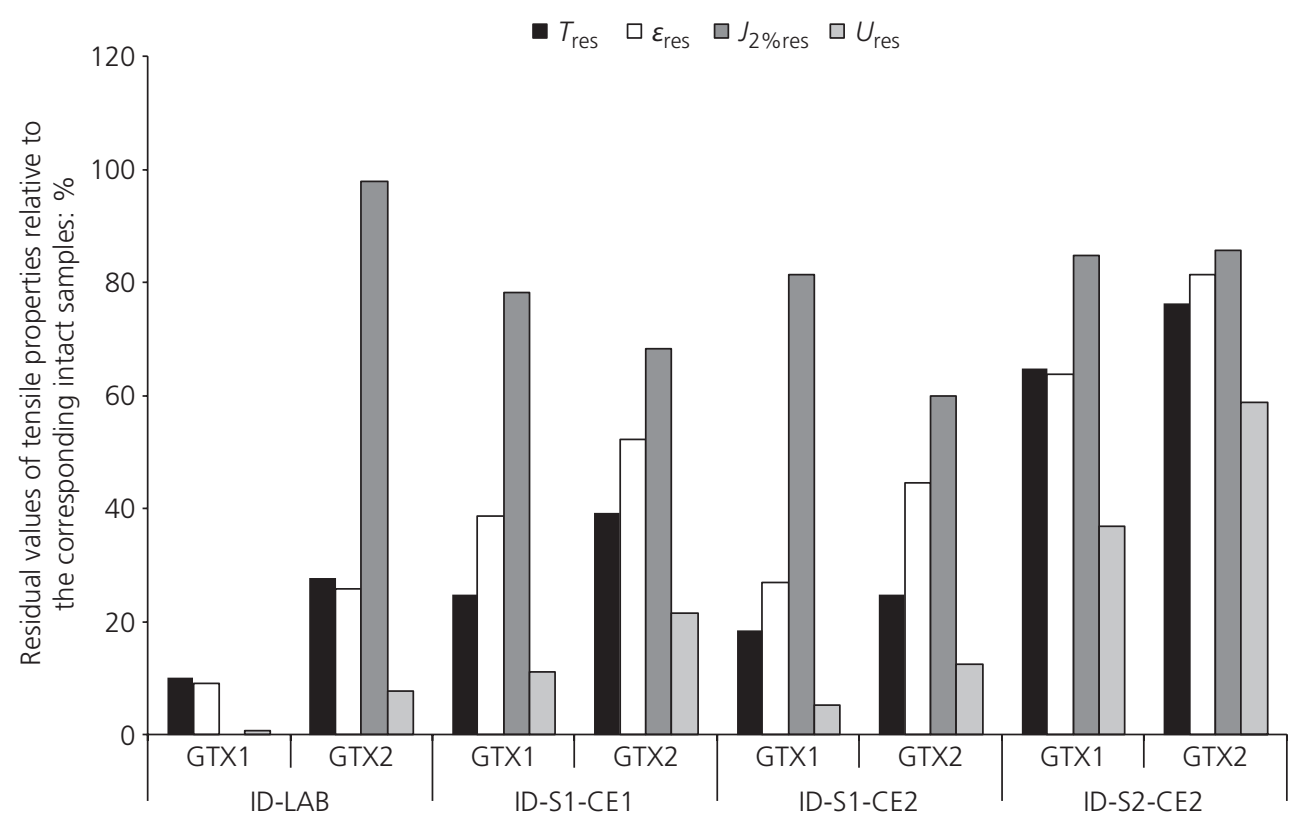

Figure 6. Residual values (\%) of tensile strength $\left(T_{\text {res }}\right)$, peak strain $\left(\varepsilon_{\text {res }}\right), 2 \%$ strain stiffness $\left(J_{2} \%\right.$ res $)$ and toughness $\left(U_{\text {res }}\right)$ of geotextiles GTX1 and GTX2 


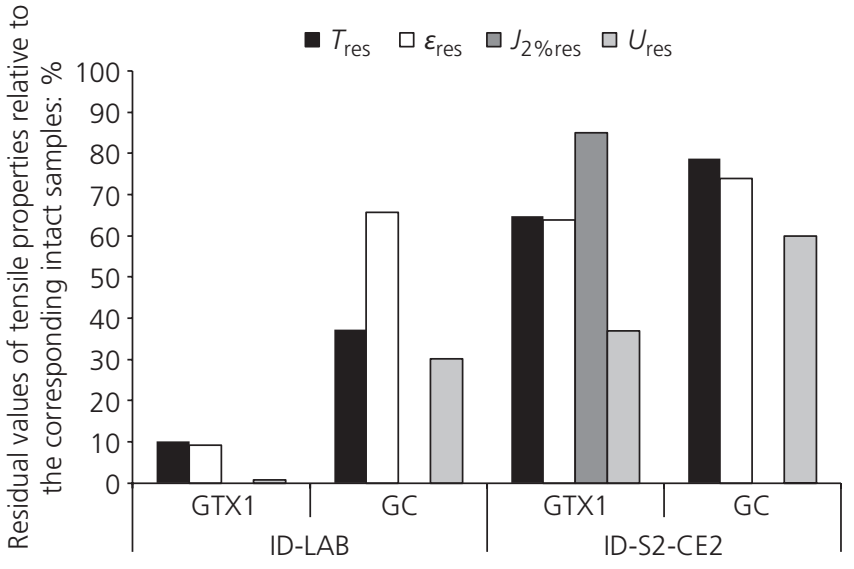

Figure 7. Residual values (\%) of tensile strength $\left(T_{\text {res }}\right)$, peak strain $\left(\varepsilon_{\text {res }}\right), 2 \%$ strain stiffness $\left(J_{2 \% \text { res }}\right)$ and toughness $\left(U_{\text {res }}\right)$ of geotextile GTX1 and geocomposite GC1 (with different structures and nominal tensile strength of $40 \mathrm{kN} / \mathrm{m}$ )

(damage induced in the laboratory, ID-LAB) and 62\% (damaged in the field in soil 2 and compaction energy 2, ID-S2-CE2).

In the installation damage tests carried out (both in the laboratory and in the field), most of the constituent tapes of GTX1 were in contact with the adjacent aggregate. Due to its woven structure, loading enables localised damage to propagate to adjacent areas. GC is constituted by a grid confined in two layers of a protective geotextile. The grid, which is likely to be the main bearing element, is thus protected from damage. Most of the visible damage was on the geotextile. When loaded during the tensile tests, the nonwoven structure of the geotextile of geocomposite GC restrained the effect of damaged fibres to their immediate vicinity.

\section{Influence of the compaction energy}

To evaluate the influence of the compaction energy used in the field trials, results for the same geosynthetic and soil type compacted to two different compaction energies (CE1 and CE2) were compared (see Table 4): geotextiles GTX1 and GTX2 after installation in soil 1 (ID-S1), woven geogrid GGw1 and geocomposite GC after installation in soil 2 (ID-S2) and woven geogrid GGw2 after installation in soil 3 (ID-S3). In most cases, increasing the compaction energy from CE1 (90\% of the standard Proctor) to CE2 (98\% of the standard Proctor) resulted in decreased residual values of the properties assessed. For example, for soil 1, such variations were wider and ranged between $+4 \%$ (for the $2 \%$ strain stiffness

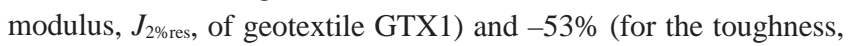
$U_{\text {res }}$, of geotextile GTX1). For soils 2 and 3, they ranged between $+24 \%$ (for the toughness, $U_{\text {res, }}$ of geocomposite GC installed in soil 2) and $-42 \%$ (for the toughness, $U_{\text {res, }}$ of extruded geogrid GGe installed in soil 3).

To achieve the defined compaction energies, several passes of the compaction equipment were necessary (variable for each soil).
The application of higher energy increases the probability of soil particles to contact the surfaces of the geosynthetics during longer periods and with higher stresses. Such effect is likely to be limited as some fragmentation of the soil particles can occur during compaction.

\section{Influence of the type of soil}

Comparing results obtained for geotextiles GTX1 and GTX2 installed in soils 1 and 2 (and the same compaction energy, CE2 - 98\% of the standard Proctor) enabled evaluation of the influence of the type of soil in the installation damage induced. For these geotextiles, using soil 1 instead of soil 2 resulted in a decrease in the residual values of the following (see Table 4): tensile strength, $71 \%$ (GTX1) and 68\% (GTX2); peak strain, 58\% (GTX1) and 45\% (GTX2); 2\% strain stiffness modulus, 4\% (GTX1) and 30\% (GTX2); toughness, 860\% (GTX1) and 79\% (GTX2).

Installation damage depends on the grain size, angularity and thickness of the fill material. As that thickness was kept constant in all the embankments built, the soils' grain sizes and angularity are the key aspects. Soil 1 (Table 2) has a wider range of sizes and larger particles, as well as a smaller percentage of fines $\left(D_{50}=11.78 \mathrm{~mm}\right.$, $D_{\max }=50.80 \mathrm{~mm}, 12 \%$ of fines $)$ than soil $2\left(D_{50}=0.38 \mathrm{~mm}\right.$, $D_{\max }=5.00 \mathrm{~mm}, 22 \%$ fines). Additionally, soil 2 is a residual soil from granite, with rounder particles, while soil 1 is an aggregate with crushed stone (including some sharp particles), thus becoming the most aggressive.

\section{Influence of the method used to induce ID}

Figure 8 relates the installation damage reduction factors after laboratory and field tests. For most cases, damage induced in the laboratory is more important than that induced in the field. For the conditions and materials used, the installation damage laboratory test is too conservative to estimate the tensile strength reduction after the installation damage trials under real conditions. The trend lines included in Figure 8 can be used to interpolate relationships between installation damage reduction factors determined in the laboratory and in the field for analogue conditions and geosynthetics.

\section{Reduction factors}

The traditional installation damage reduction factor (Table 6), $R F_{\mathrm{ID}}$, representing reductions of tensile strength, ranged between 1.06 (for woven geogrid GGw1 after installation in soil 1 and the lowest compaction energy considered, ID-S2-CE1) and 9.93 (for geotextile GTX1 after installation damage in the laboratory, ID-LAB). All values were larger than 1.0 (minimum to be used in design), reflecting a decrease of the mean tensile strength after installation damage. The values for the reduction factor for installation damage considering the $2 \%$ strain stiffness, $R F_{\mathrm{ID} \mathrm{Jsec} 2} \%$, were lower (Table 6), ranging between 0.99 (for the extruded geogrid GGe after installation in soil 3 with the lowest compaction energy, ID-S3-CE1) and 1.67 (for geotextile GTX2 after installation in soil 1 with the highest compaction energy, ID-S1-CE2). As reported in the literature, in many cases, this quantity better reflects the actual response of the materials in service. The variation of 


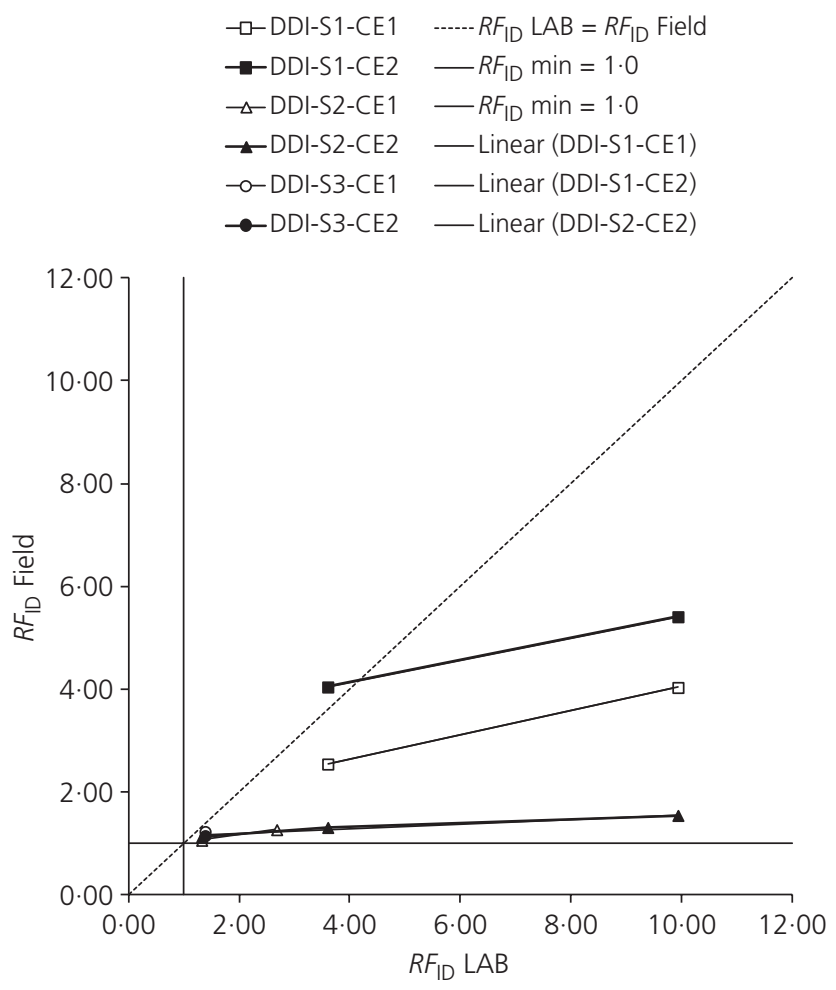

Figure 8. Installation damage reduction factors of the geosynthetics studied after damage induced in the laboratory tests and after field installation damage trials the reduction factors for installation damage, $\Delta R F_{\mathrm{ID}}$ (Equation 10 ), represents the conservativeness of using the tensile strength response of the geosynthetics after installation damage $\left(R F_{\mathrm{ID}}\right)$ instead of the corresponding changes in stiffness $\left(R F_{\mathrm{ID} \mathrm{Jsec}} \%\right)$. Those values ranged between $-4 \%$ and $-77 \%$ and were particularly high for both geotextiles GTX1 ( $-24 \%$ to $-77 \%)$ and GTX2 (-11\% to $-72 \%)$, indicating that the changes in the tensile strength largely overestimated the corresponding reductions in stiffness.

For ultimate limit states where there is tensile failure of geosynthetics, the traditional reduction factor for installation damage should be considered. For ultimate limit states not involving the geosynthetics' tensile failure or for serviceability limit states, the variation of the materials' stiffness can be conveniently accounted for. The reduction factors for installation damage for GTX1 are very high (1.54 to 9.93), as this material is hardly adequate for permanent soil reinforcement application.

Installation damage reduction factors were estimated (Table 7) according to Hufenus et al. (2005). Equations 7 and 8 were used, respectively, to determine the best fit for the reduction factors for installation damage, $R F_{\mathrm{ID}}$ (estim), and the corresponding maximum

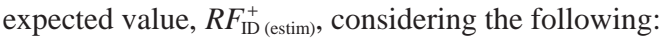

- For the type of geosynthetic: geotextiles GTX1 and GTX2, $r f_{\mathrm{G}}=1 \cdot 12$ (slit tape woven); woven geogrids GGw1 and GGw2, $r f_{\mathrm{G}}=1.08$ (coated grid); extruded geogrid GGe, $r f_{\mathrm{G}}=1.00$ (uniaxial stretched grid); geocomposite GC, $r f_{\mathrm{G}}=1.08$ (coated grid).

\begin{tabular}{|c|c|c|c|c|c|c|c|}
\hline Material & Sample & $r f_{G}$ & $r f_{B}$ & $r f_{C}$ & $r f_{\mathrm{p}}$ & $R F_{\mathrm{ID}}$ (estim) & $R F_{1 \mathrm{D}}^{+}$(estim) \\
\hline \multirow[t]{4}{*}{ GTX1 } & ID-LAB & $1 \cdot 12$ & $1 \cdot 10$ & 1.08 & $1 \cdot 19$ & $1 \cdot 58$ & $3 \cdot 0$ \\
\hline & ID-S1-CE1 & $1 \cdot 12$ & $1 \cdot 10$ & 1.08 & $1 \cdot 19$ & 1.58 & $3 \cdot 0$ \\
\hline & ID-S1-CE2 & $1 \cdot 12$ & $1 \cdot 10$ & 1.08 & $1 \cdot 19$ & $1 \cdot 58$ & $3 \cdot 0$ \\
\hline & ID-S2-CE2 & $1 \cdot 12$ & 1.03 & 1.08 & 1.00 & $1 \cdot 25$ & 1.9 \\
\hline \multirow[t]{4}{*}{ GTX2 } & ID-LAB & $1 \cdot 12$ & $1 \cdot 10$ & 1.08 & $1 \cdot 19$ & 1.58 & $3 \cdot 0$ \\
\hline & ID-S1-CE1 & $1 \cdot 12$ & $1 \cdot 10$ & 1.08 & $1 \cdot 19$ & 1.58 & $3 \cdot 0$ \\
\hline & ID-S1-CE2 & $1 \cdot 12$ & $1 \cdot 10$ & 1.08 & $1 \cdot 19$ & $1 \cdot 58$ & $3 \cdot 0$ \\
\hline & ID-S2-CE2 & $1 \cdot 12$ & 1.03 & 1.08 & 1.00 & 1.25 & 1.9 \\
\hline \multirow[t]{3}{*}{ GGw1 } & ID-LAB & 1.08 & $1 \cdot 10$ & 1.08 & $1 \cdot 19$ & 1.53 & $2 \cdot 8$ \\
\hline & ID-S2-CE1 & 1.08 & 1.03 & 1.08 & 1.00 & $1 \cdot 20$ & 1.8 \\
\hline & ID-S2-CE2 & 1.08 & 1.03 & 1.08 & 1.00 & $1 \cdot 20$ & $1 \cdot 8$ \\
\hline \multirow[t]{3}{*}{ GGw2 } & ID-LAB & 1.08 & $1 \cdot 10$ & 1.08 & $1 \cdot 19$ & $1 \cdot 53$ & $2 \cdot 8$ \\
\hline & ID-S3-CE1 & 1.08 & $1 \cdot 10$ & 1.08 & 1.00 & $1 \cdot 28$ & $2 \cdot 0$ \\
\hline & ID-S3-CE2 & 1.08 & $1 \cdot 10$ & 1.08 & 1.00 & 1.28 & $2 \cdot 0$ \\
\hline \multirow[t]{2}{*}{ GGe } & ID-S3-CE1 & 1.00 & $1 \cdot 10$ & 1.08 & 1.00 & $1 \cdot 19$ & $1 \cdot 8$ \\
\hline & ID-S3-CE2 & 1.00 & $1 \cdot 10$ & 1.08 & 1.00 & $1 \cdot 19$ & 1.8 \\
\hline \multirow[t]{3}{*}{$\mathrm{GC}$} & $L A B$ & 1.08 & $1 \cdot 10$ & 1.08 & $1 \cdot 19$ & 1.53 & $2 \cdot 8$ \\
\hline & ID-S2-CE1 & 1.08 & 1.03 & 1.08 & 1.00 & $1 \cdot 20$ & $1 \cdot 8$ \\
\hline & ID-S2-CE2 & 1.08 & 1.03 & 1.08 & 1.00 & $1 \cdot 20$ & 1.8 \\
\hline
\end{tabular}

Table 7. Estimates of the installation damage reduction factors for the tensile strength using the matrix from Hufenus et al. (2005) 
- For the fill material: laboratory aggregate and soil 1 (S1), $r f_{\mathrm{B}}=1 \cdot 10$ (angular coarse-grained soil $<150 \mathrm{~mm}$ ); soil 2 (S2), $r f_{\mathrm{B}}=1.03$ (rounded coarse-grained soil $<150 \mathrm{~mm}$ ).

- For the compaction energy: $r f_{\mathrm{C}}=1.08$ (high ground pressure $>55 \mathrm{kPa}$ ).

- For the number of passes: $r f_{\mathrm{N}}=1 \cdot 19$ (maximum compaction ( $>8$ passes)) for soil $1 ; r f_{\mathrm{N}}=1.00$ (standard compaction (3-8 passes)) for soil 2.

For geotextiles GTX1 and GTX2 and the most severe installation conditions considered, these estimates can be unsafe, namely after installation damage in the laboratory, ID-LAB, and in soil 1 with the highest compaction energy, ID-S1-CE2, for GTX1 and GTX2, and after installation in soil 1 and compaction to the lowest energy, ID-S1-CE1, for GTX1. Alternatively, using $r f_{\mathrm{G}}=$ 1.26 (woven fabric) for geotextiles GTX1 and GTX2 led to the same conclusions. For the woven geogrids GGw1 and GGw2 and for the extruded geogrid GGe (after installation damage induced in the laboratory, ID-LAB, and in the field in soil 3 compacted to the lowest energy, ID-S3-CE1), these estimates were very conservative, as the measured values for the reduction factor for installation damage, $R F_{\mathrm{ID}}$, were lower than the estimated interval. For the remaining materials and installation damage conditions, the reduction factor for installation damage, $R F_{\mathrm{ID}}$, was well estimated by the matrix used. The following are possible reasons for the differences found: the coefficient of determination of Equation 7 to the data used to derive the proposal by Hufenus et al. (2005) is low (0.39), and of the tests (470) considered by Hufenus et al. (2005), only $6 \%$ and $21 \%$ referred to slit tape woven materials and woven fabrics, respectively, and 18\% included maximum compaction ( $>8$ passes).

\section{Bias statistics}

To contribute to enlarging databases available in the literature, Table 6 includes a bias statistics analysis, representing the reinforcement strength variability immediately after installation using the methodology described by Bathurst et al. (2011). Geocomposite GC and extruded geogrid GGe had the lowest and the highest variability: 1.03 and 1.23 , respectively. All values were higher than the minimum (1.0).

According to Bathurst et al. (2011), it is likely that bias statistics are different for geosynthetics tested in the field and in the laboratory using synthetic aggregates. In this work, the geosynthetics considered refer to materials taken from the same roll and lot; hence, the bias statistics, $X_{\mathrm{ID}}$, is the same for all types of damage induced (including in the laboratory) for each geosynthetic. In this case, the installation damage bias statistics $\left(X_{\mathrm{ID}}\right)$ only depended on the coefficient of variation of the measured tensile strength of undamaged specimens. Bathurst et al. (2011) also affirm that the inherent variability of tensile strength of the geosynthetic strength ( $\left.T_{\text {ult,meas }}\right)$ is included in the statistics for $X_{\mathrm{ID}}$. The differences between types of damage test are reflected in the corresponding values of the reduction factor for installation damage, $R F_{\text {ID. }}$.

\section{Correlations}

Figure 9 relates the reduction factor for installation damage, $R F_{\mathrm{ID}}$, of geotextiles GTX1 and GTX2, determined from $T_{\max }$ and $J_{\text {sec } 2 \% \text {, with }}$ the average soil grain size $\left(D_{50}\right)$. Following recommendations in EN ISO/TR 20432 (IPQ, 2007), Figure 9 can be used to interpolate values of the reduction factor for installation damage, $R F_{\mathrm{ID}}$, for the design of geosynthetics of the same family of products installed under similar conditions in soils with $D_{50}$ between $0.38 \mathrm{~mm}$ (soil 2) and $11.78 \mathrm{~mm}$ (soil 1). Using the tensile strength to represent the geotextiles' behaviour was the most conservative approach.

Figure 10 relates the reduction factor for installation damage, $R F_{\text {ID }}$, with the measured tensile strength of the undamaged geosynthetics. For the same compaction energy (CE2, 98\% of the soil standard Proctor), the results seem to indicate that soil 1 is more aggressive than soils 2 and 3 . Soils 1 and 3 are similar materials and the apparent differences in results are likely to be due to the type of geosynthetics considered with these soils: the geotextiles GTX1 and GTX2 installed in soil 1 are more sensitive to installation damage than the woven geogrid GGw2 and the extruded geogrid GGe (used with soil 3). These results indicate greater importance of the structure of the geosynthetics for their survivability after installation than the type of soil where they are installed. If the nominal strength of the geosynthetics was used in Figure 10, instead of their measured tensile strength, the trend observed would be different. For the same compaction energy ( $98 \%$ of the standard Proctor of the soils), Figure 10 helps to point out that (a) geosynthetics with higher measured tensile strength were less affected by the installation damage induced, independently of the type of soil where they were installed; (b) for the same geosynthetics (geotextiles GTX1 and GTX2), soil 2 is more aggressive than soil 1; and (c) for similar

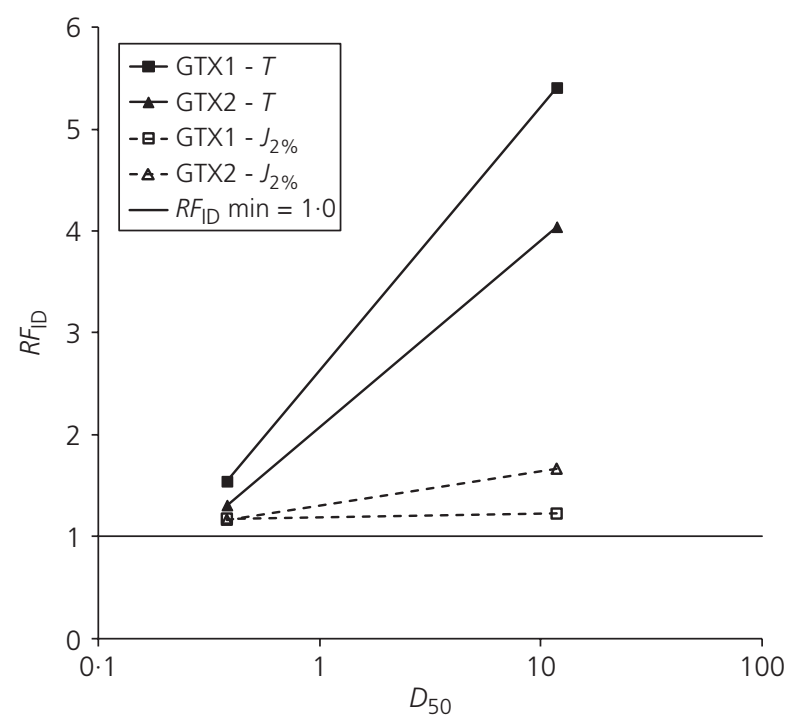

Figure 9. Correlation of the reduction factor for installation damage (tensile strength $(T)$ and for the $2 \%$ secant stiffness $\left(J_{2} \%\right)$ ) and the average grain size of the soil $\left(D_{50}\right)$ 


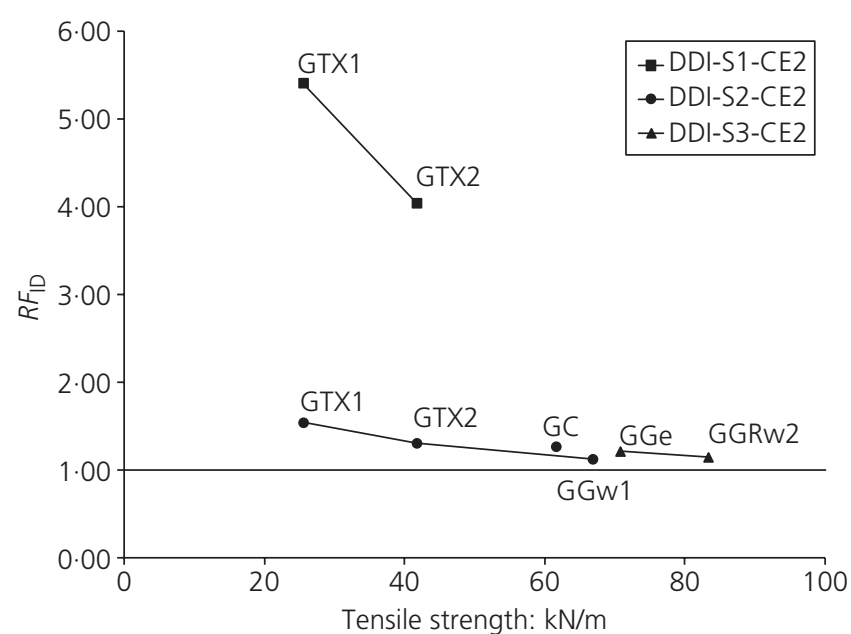

Figure 10. Correlation of the reduction factor for installation damage (tensile strength $(T)$ ) and the tensile strength of the geosynthetics

soils (as soils 1 and 3), the consequences of installation damage seem highly dependent on the type of geosynthetic, as evident from the reduction factors obtained for the geotextiles GTX1 and GTX2, installed in soil 1, and geogrids GGe and GGw2, in contact with soil 3.

\section{Conclusions}

The tensile behaviour of six geosynthetics after installation damage induced in the laboratory and in field trials was investigated. Samples were visually inspected using scanning electron microscopy. Widewidth tensile tests were done on intact and damaged samples. Given the results obtained, the main conclusions are as follows.

- Visual inspections indicate that the damage resulting from installation damage induced in the laboratory can be more severe than that induced in field trials; woven products, particularly geotextiles GTX1 and GTX2, are apparently more sensitive to installation damage.

- For geotextiles GTX1 and GTX2, higher nominal strength is likely to ensure higher resistance to installation damage, as observed for the tensile strength, peak strain and toughness; however, the $2 \%$ strain stiffness (more likely to represent the tensile response of the geosynthetic during service) was affected conversely.

- Geocomposite GC, constituted by three layers of geosynthetics, better endured installation damage, when compared with a woven material (GTX1) with similar nominal tensile strength; woven structures tend to enable the propagation of damage when the geosynthetic is loaded.

- Increasing the compaction energy resulted in more severe damage, namely for geotextiles GTX1 and GTX2; this trend is likely to have an upper limit (when the aggregate tends to fragment).
- The soil with larger particles (soil 1) induced the most significant damage. The type of geosynthetic can be more important than the type of fill material used, as indicated by the results from geotextiles GTX1 and GTX2 after installation in soil 1 and geogrid GGe and geocomposite GC installed in soil 3.

- The laboratory test used to induce installation damage led to reductions of the assessed properties larger than the field trials. Its importance depends on the analysed property.

- Bias statistics were estimated, to be used in a limit state design by applying it to the deterministic predictions. Contrary to what the literature suggests, values for geosynthetics tested in the field and in the laboratory (with synthetic aggregates) were equal; this can be due to using the same set of results as a reference (undamaged samples) to assess the damage induced.

- The installation damage reduction factors determined range between 1.06 (for woven geogrid GGw1 installed in soil 2 compacted to the lowest energy, ID-S2-CE1) and 9.93 (geotextile GTX1 after damage induced in the laboratory, ID-LAB). Except for the geosynthetics most affected by installation damage, these reduction factors were well estimated by a proposal from the literature.

- Correlations between the installation damage reduction factor and representative information of the soil grain sizes and the tensile strength of the intact material were proposed. These can be used to interpolate installation damage reduction factors for similar conditions.

- It is suggested that, in some cases, the secant stiffness modulus for relevant strain level is considered to represent the tensile response of the geosynthetics, instead of their tensile strength. This is only possible if the design refers to limit ultimate states without tensile failure of the geosynthetic or to serviceability limit states. More realistic and economic designs can then be achieved.

\section{Acknowledgements}

The authors would like to extend their thanks for the financial support of FCT, Research Project PTDC/ECM/099087/2008, and COMPETE, Research Project FCOMP-01-0124-FEDER-009724.

\section{REFERENCES}

Allen TM and Bathurst RJ (1994) Characterization of geosynthetic load-strain behavior after installation damage. Geosynthetics International 1(2): 181-199.

ASTM (1991) D698-91: Test method for laboratory compaction characteristics of soil using standard effort $\left(12,400 \mathrm{ft}-\mathrm{lb} / \mathrm{ft}^{3}\right)$. ASTM International, West Conshohocken, PA, USA.

Bathurst RJ, Huang B and Allen TA (2011) Analysis of installation damage tests for LRFD calibration of reinforced soil structures. Geotextiles and Geomembranes 29(3): 323-334.

Bathurst RJ, Huang B and Allen TA (2012) Interpretation of laboratory creep testing for reliability-based analysis and load and resistance factor design (LRFD) calibration. Geosynthetics International 19(1): 39-53. 
Greenwood JH (1998) The nature of mechanical damage. In Seminar Volume on Installation Damage in Geosynthetics. ERA Report 98-0853, ERA Technology Ltd., Leatherhead, UK. pp. 1.1.1-1.1.15.

Huang C-C and Wang Z-H (2007) Installation damage of geogrids: influence of load intensity. Geosynthetics International 14(2): 65-75.

Hufenus R, Ruegger R, Flum D and Sterba IJ (2005) Strength reduction factors due to installation damage of reinforcing geosynthetics. Geotextiles and Geomembranes 23(5): 401-424.

IPQ (Portuguese Institue for Quality) (1998) ENV ISO 107221:1998: Geotextiles and geotextile-related products Procedure for simulating damage during installation — Part 1: Installation in granular materials. IPQ, Caparica, Portugal.

IPQ (2007) EN ISO/TR 20432:2007: Guidelines to the determination of long-term strength of geosynthetics for soil reinforcement. IPQ, Caparica, Portugal.

IPQ (2008) EN ISO 10319:2008: Geosynthetics. Wide-width tensile test. IPQ, Caparica, Portugal.

Koerner GR and Koerner RM (1990) The installation survivability of geotextiles and geogrids. In Proceedings of the 4th
International Conference on Geotextiles, Geomembranes and Related Products, Rotterdam, the Netherlands (Den Hoedt G (ed.)). A.A. Balkema, Brookefield, Rotterdam. pp. 597-602. Mendes MJA, Palmeira EM and Matheus E (2007) Some factors affecting the in-soil load-strain behaviour of virgin and damaged nonwoven geotextiles. Geosynthetics International 14(1): 39-50.

Shukla SK (2011) Fundamental of geosynthetics. In Handbook of Geosynthetic Engineering (Shukla SK (ed.)). ICE Publishing, London, UK. pp. 1-44.

Watn A and Chew SH (2002) Geosynthetic damage — from laboratory to field. Proceedings of the 7th International Conference on Geosynthetics, Nice, France (Delmas Ph, Gourc JP and Girard H (eds.)). A.A Balkema Publishers, Lisse / Abingdon / Exton (PA)/ Tokyo, 4, pp. 1203-1226.

Watts GRA and Brady KC (1990) Site damage trials on geotextiles. In Proceedings of the 4th International Conference on Geotextiles, Geomembranes and Related Products, Rotterdam, the Netherlands (Den Hoedt G (ed.)). A.A. Balkema, Brookefield, Rotterdam. pp. 603-607. 


\section{Supplementary figures}

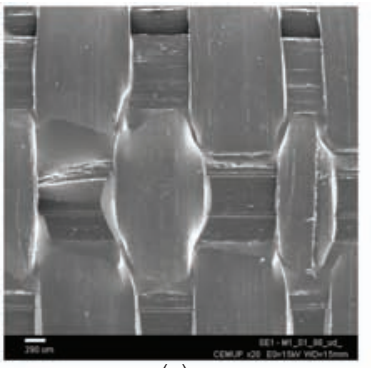

(a)

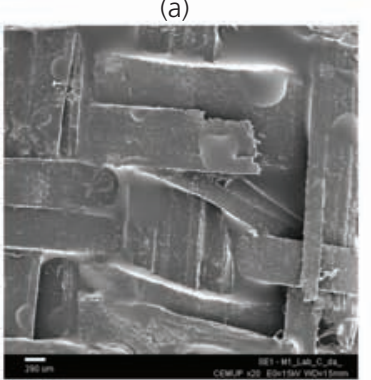

(d)

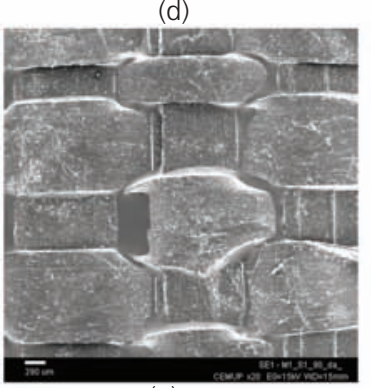

(g)
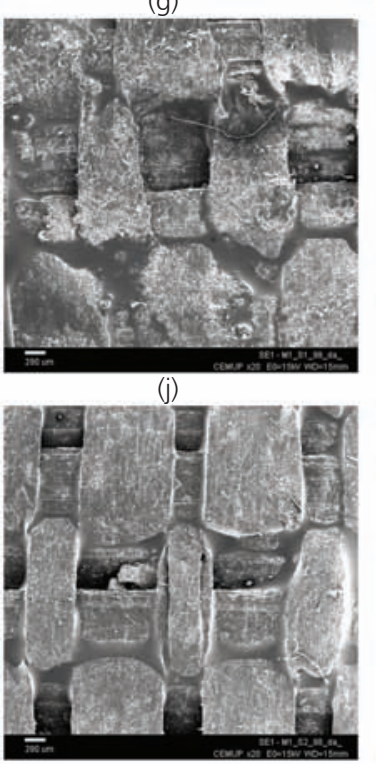

(m)
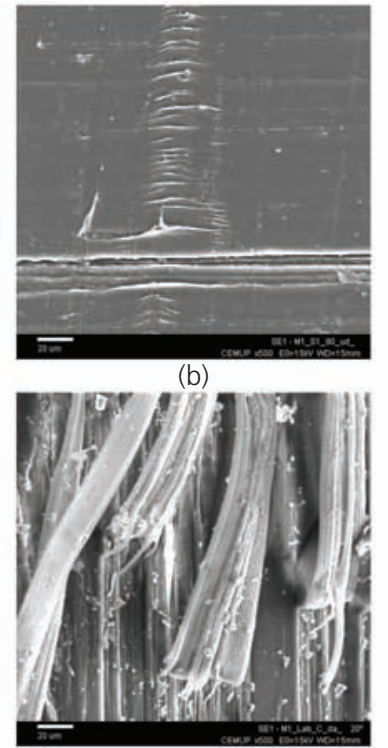

(e)

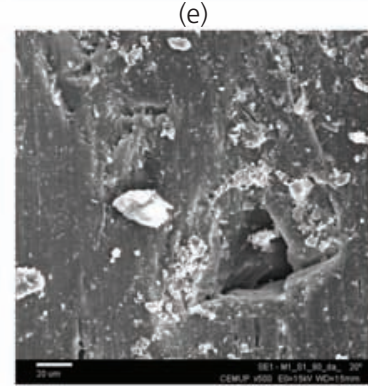

(h)

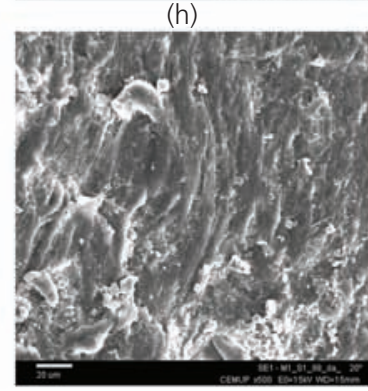

(k)

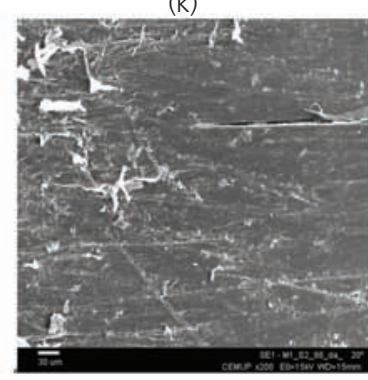

(n)
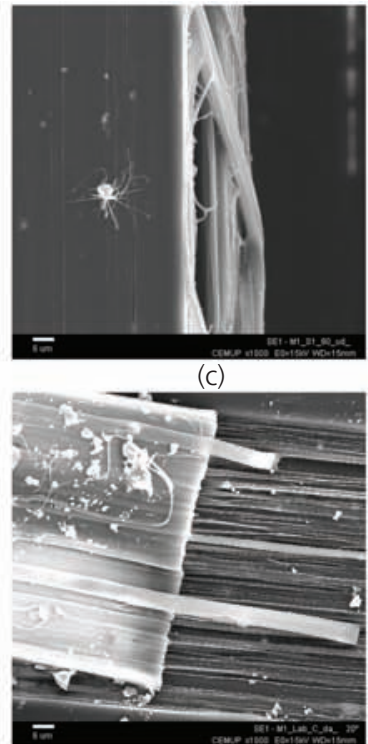

(f)
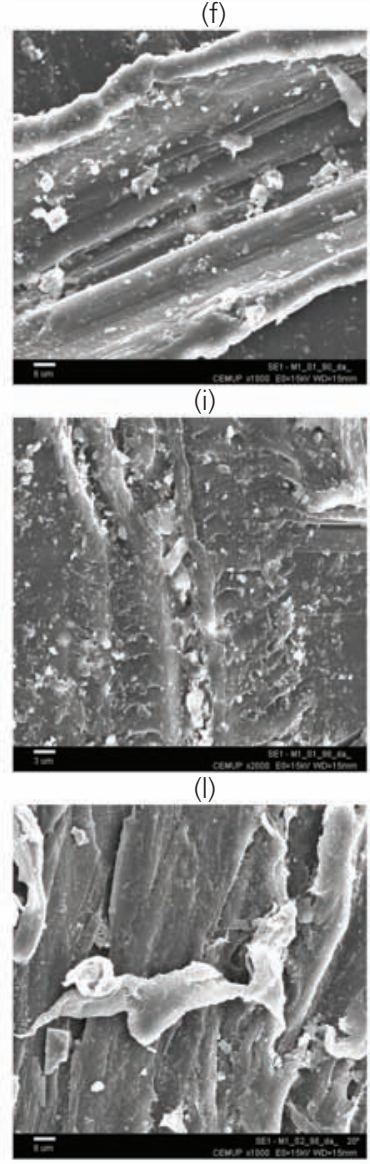

(o)
Figure 2. SEM images of geotextile GTX1: intact (INT) - (a) $\times 20$, (b) $\times 500$, (c) $\times 1000$; damaged in laboratory (ID LAB) - (d) $\times 20$, (e) $\times 500$, (f) $\times 1000$; installed in soil 1 compacted to compaction energy 1 (ID-S1-CE1) - (g) $\times 20$, (h) $\times 500$, (i) $\times 1000$; installed in soil 1 compacted to compaction energy 2 (ID-S1-CE2) - (j) $\times 20$, (k) $\times 500,(\mathrm{I}) \times 2000$; installed in soil 2 compacted to compaction energy 2 (ID-S2-CE2) - (m) ×20, (n) ×500, (o) ×1000 

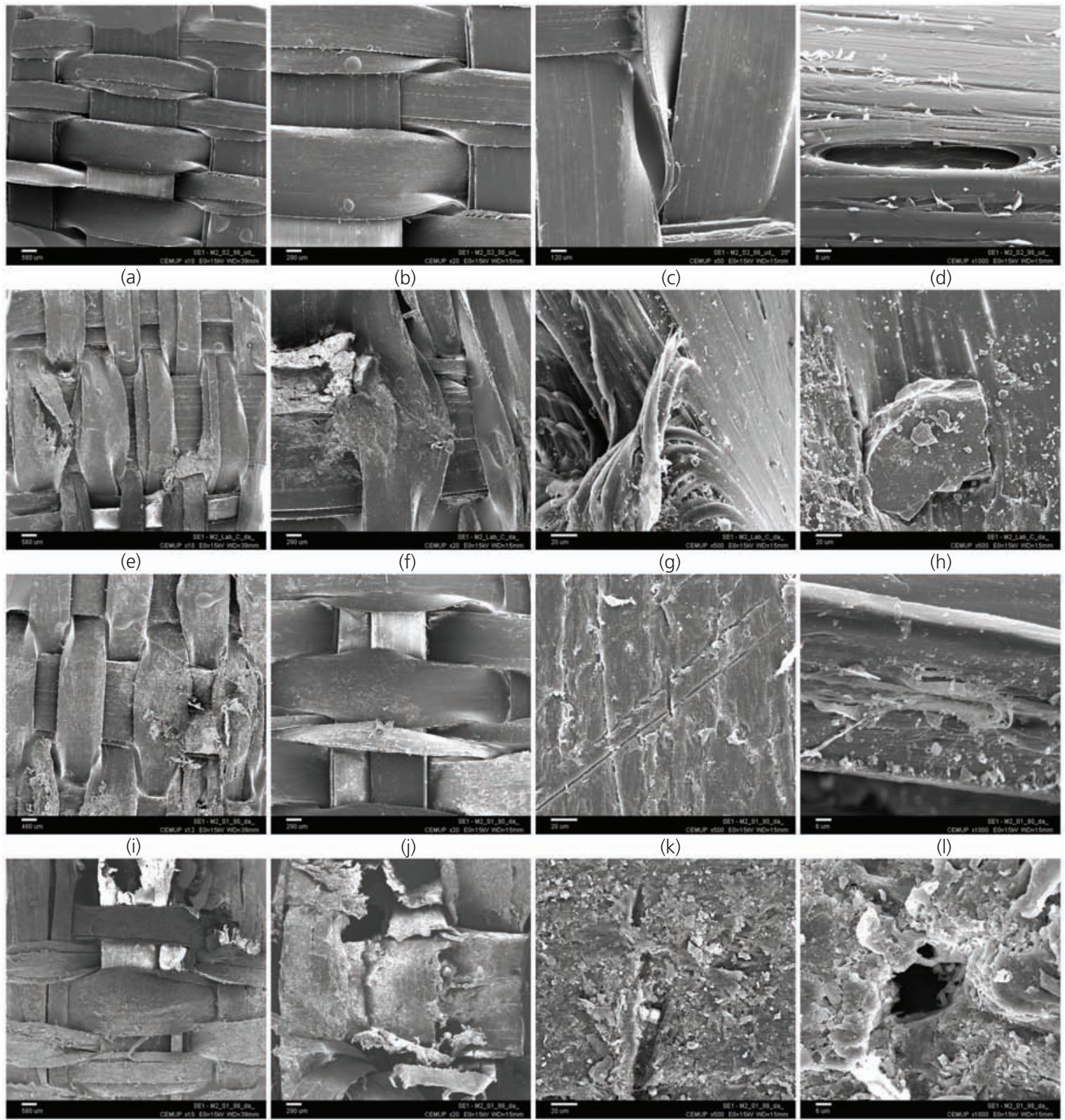

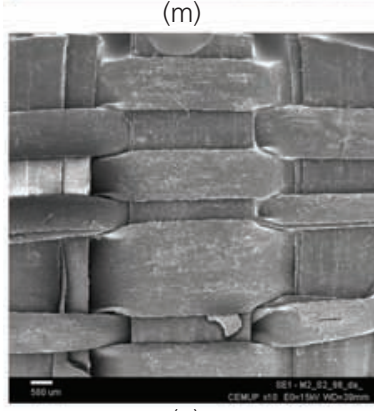

(q)
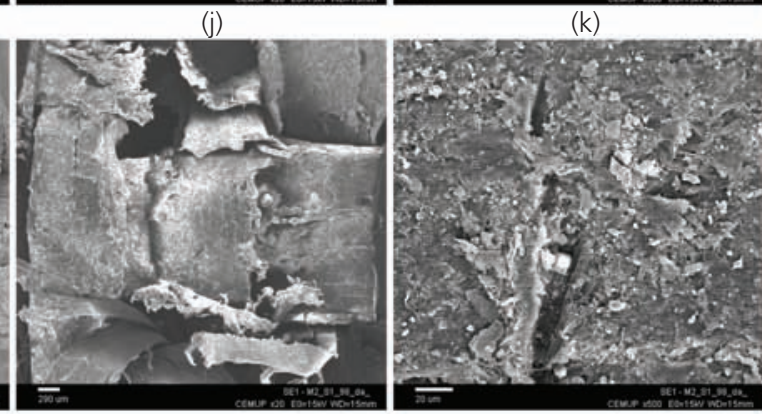

(o)

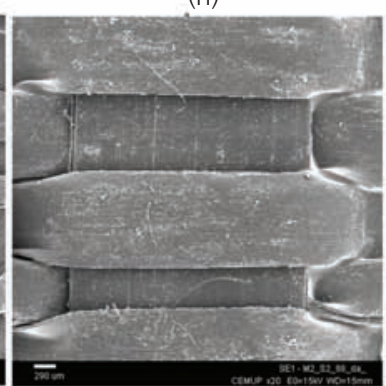

(r)

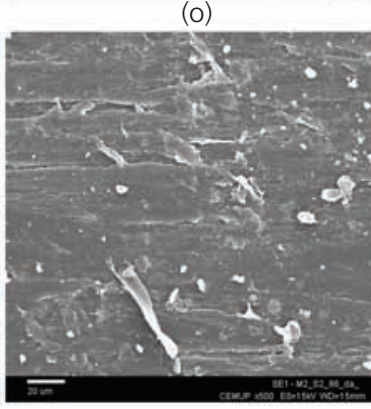

(s) (h)

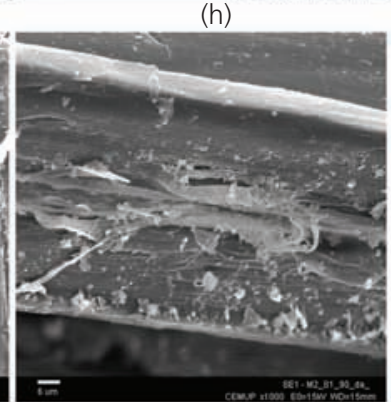

(I)
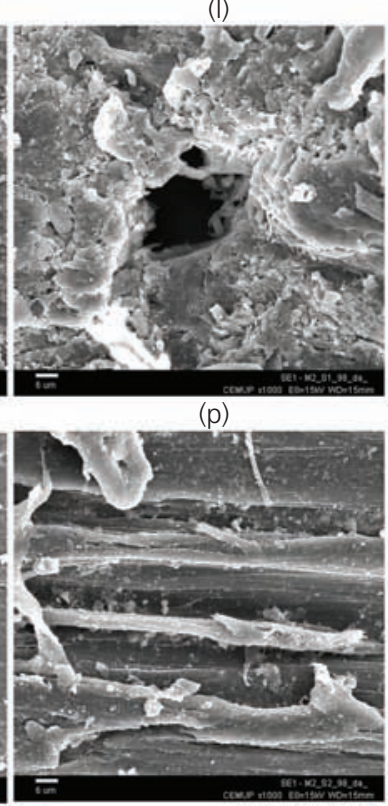

(t)
Figure 3. SEM images of geotextile GTX2: intact (INT) - (a) $\times 10$, (b) $\times 20,(c) \times 500$, (d) $\times 1000$; damaged in laboratory (ID LAB) (e) $\times 10$, (f) $\times 20,(g) \times 500$, (h) $\times 500$; installed in soil 1 compacted to compaction energy 1 (ID-S1-CE1) - (i) $\times 12$, (j) $\times 20$, (k) $\times 500$,
(I) $\times 1000$; installed in soil 1 compacted to compaction energy 2 $($ ID-S1-CE2) - (m) $\times 10,(n) \times 20$, (o) $\times 500,(p) \times 1000$; installed in soil 2 compacted to compaction energy 2 (ID-S2-CE2) - (q) $\times 10$, (r) $\times 20,(s) \times 500,(t) \times 1000$ 


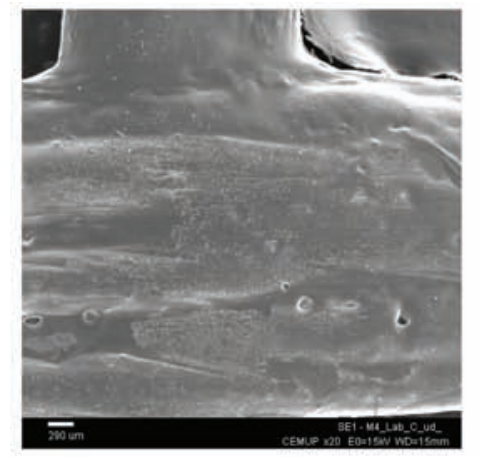

(a)

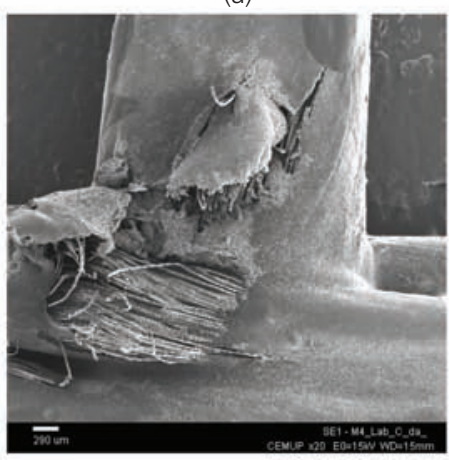

(d)

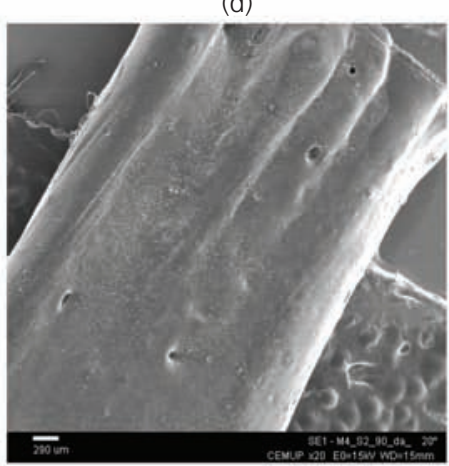

(g)

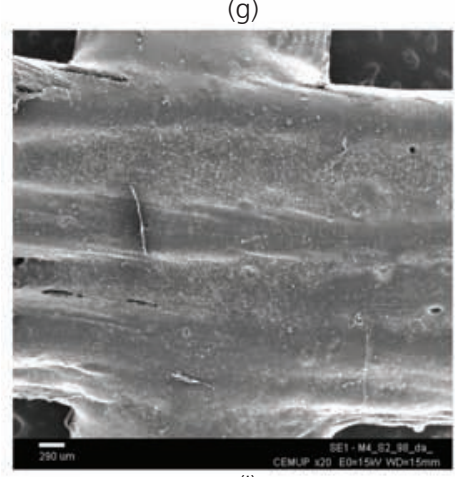

(j)

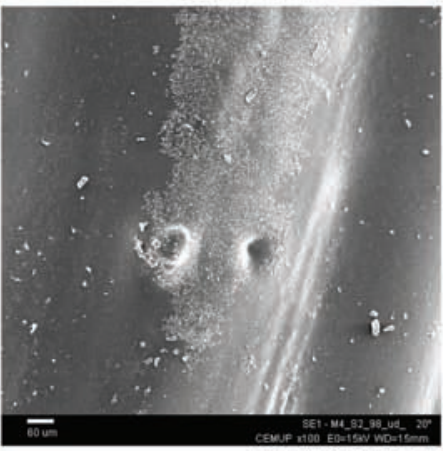

(b)

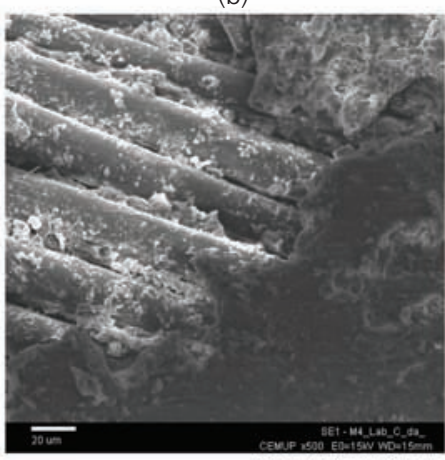

(e)

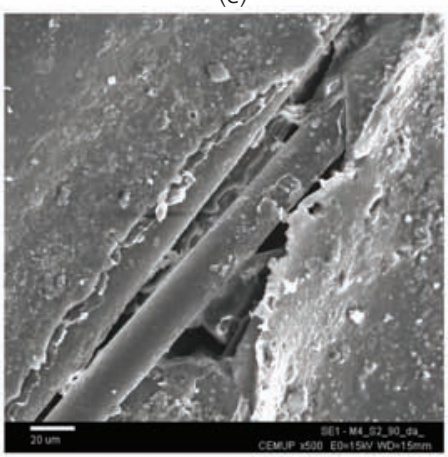

(h)

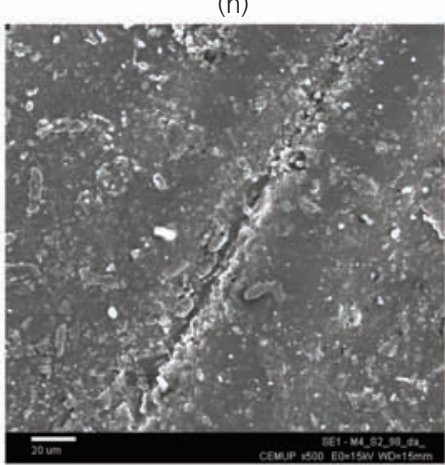

(k)

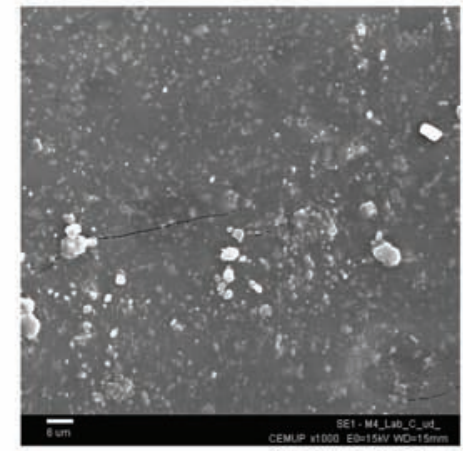

(c)

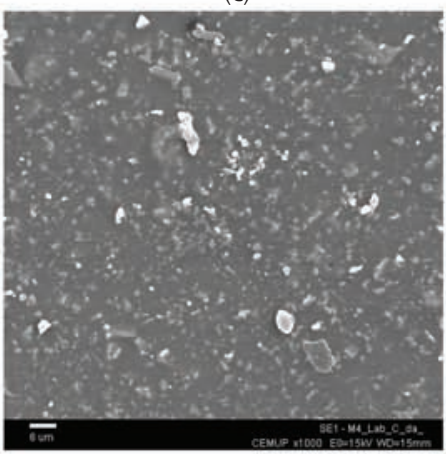

(f)

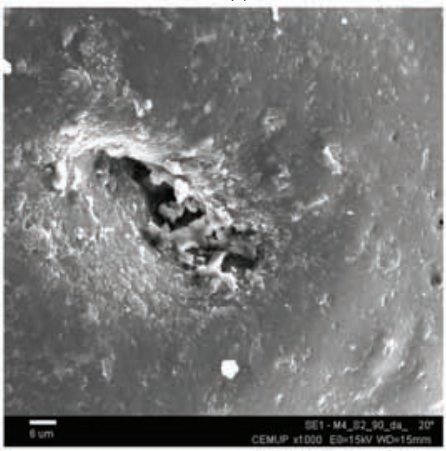

(i)

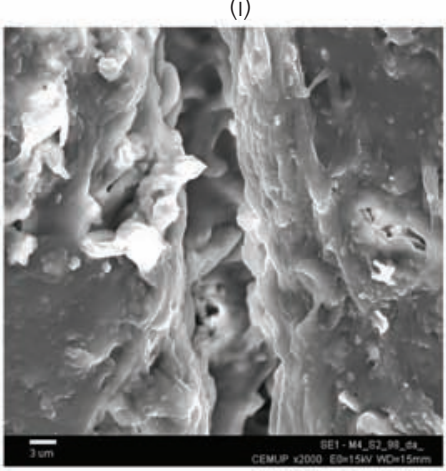

(l)
Figure 4. SEM images of woven geogrid GGw1: intact (INT) (a) $\times 20$, (b) $\times 500$, (c) $\times 1000$; damaged in laboratory (ID LAB) (d) $\times 20$, (e) $\times 500$, (f) $\times 1000$; installed in soil 2 compacted to compaction energy 1 (ID-S2-CE1) - (g) ×20, (h) ×500, (i) ×1000; installed in soil 2 compacted to compaction energy 2 $($ ID-S2-CE2) - (j) $\times 20,(k) \times 500$, (I) $\times 2000$ 

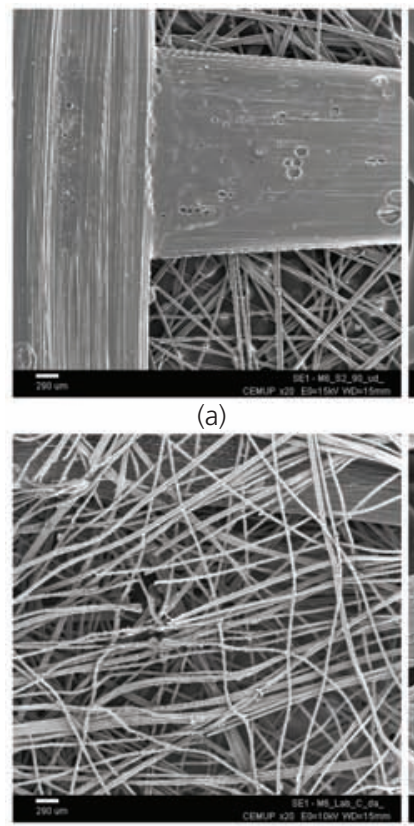

(e)

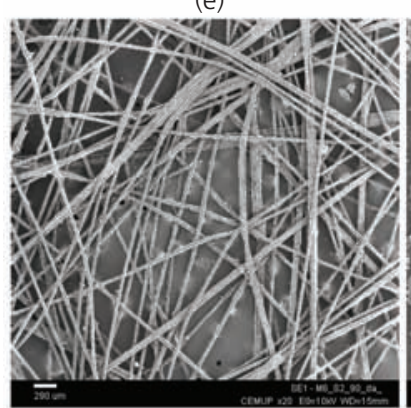

(i)

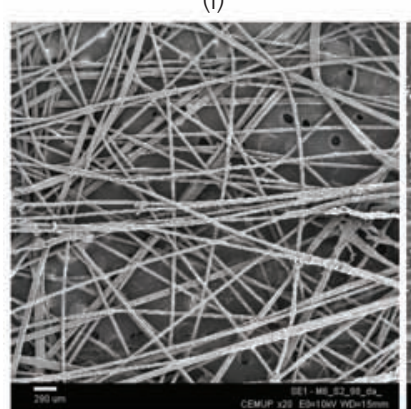

(m)

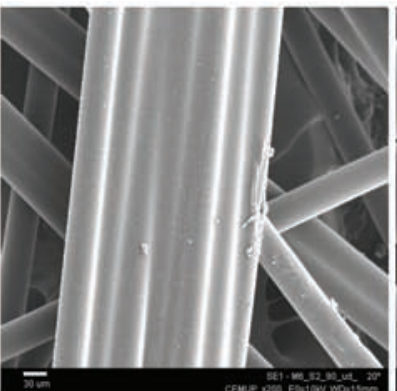

(b)

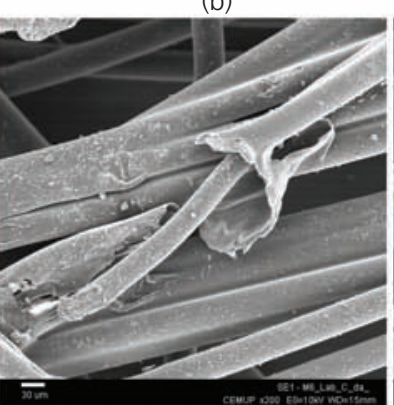

(f)

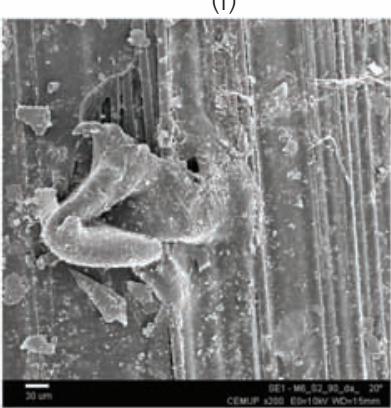

(j)

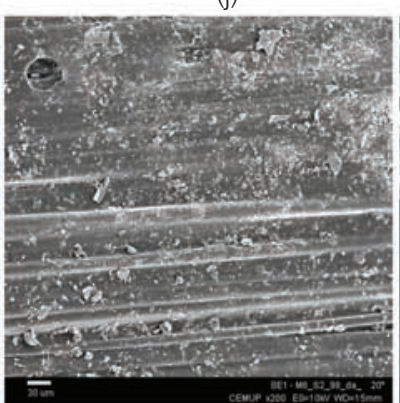

(n)

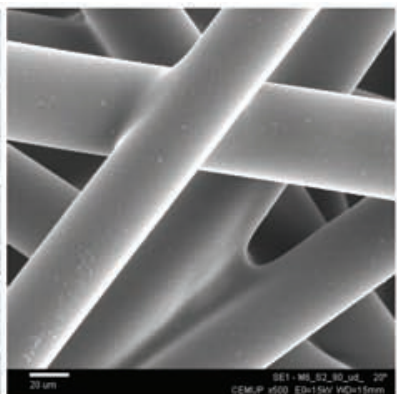

(c)

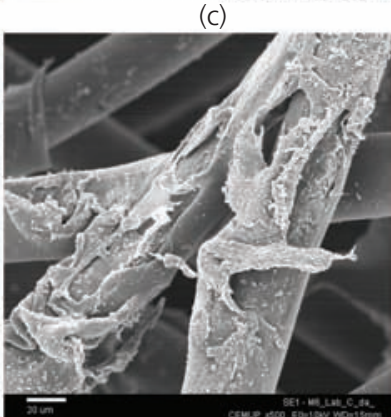

(g)

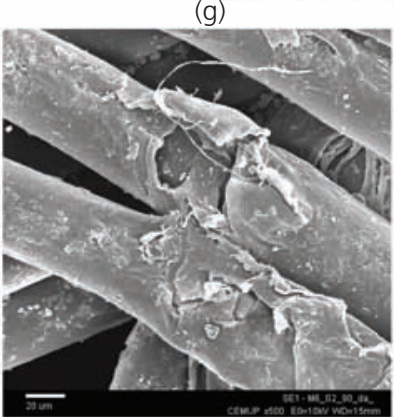

(k)

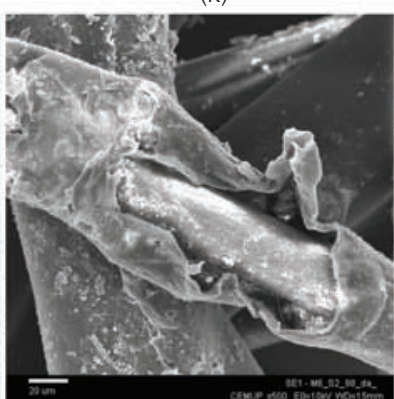

(0)

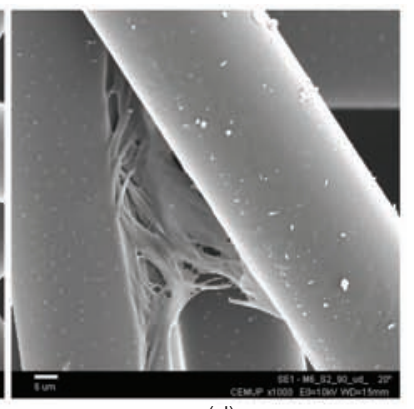

(d)

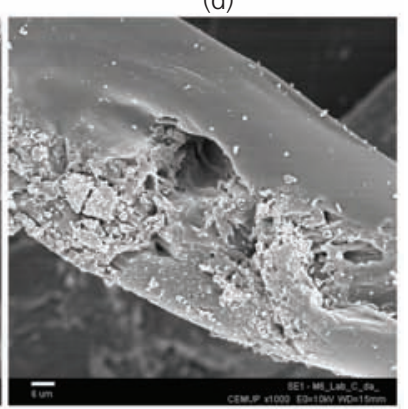

(h)

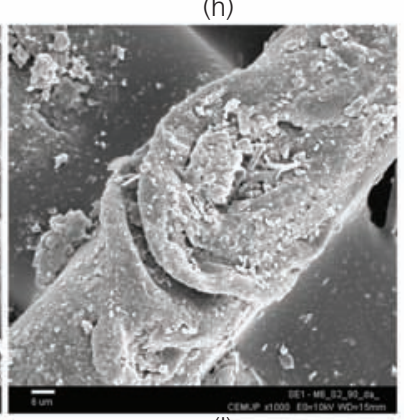

(l)

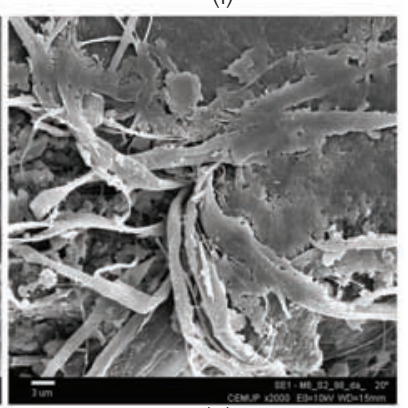

(p)
Figure 5. SEM images of geocomposite GC: intact (INT) - (a) $\times 20$, (b) $\times 200$, (c) $\times 500$, (d) $\times 1000$; damaged in laboratory (ID LAB) (e) $\times 20$, (f) $\times 200$, (g) $\times 500$, (h) $\times 1000$; installed in soil 2 compacted to compaction energy 1 (ID-S2-CE1) - (i) $\times 20$, (j) $\times 200$, (k) $\times 500,(I) \times 1000$; installed in soil 2 compacted to compaction energy 2 (ID-S2-CE2) - (m) ×20, (n) ×200, (o) $\times 500$, (p) $\times 2000$

\section{WHAT DO YOU THINK?}

To discuss this paper, please submit up to 500 words to the editor at www.editorialmanager.com/envgeo. Your contribution will be forwarded to the author(s) for a reply and, if considered appropriate by the editorial panel, will be published as a discussion in a future issue of the journal. 